University of Nebraska - Lincoln

DigitalCommons@University of Nebraska - Lincoln

Agronomy \& Horticulture - Faculty Publications

Agronomy and Horticulture Department

3-27-2011

\title{
A First Insight into Population Structure and Linkage Disequilibrium in the U.S. Peanut Minicore Collection
}

\author{
Vikas Belamkar \\ University of Nebraska-Lincoln, vikas.belamkar@unl.edu \\ Michael Gomez Selvaraj \\ Texas A\&M System \\ Jamie L. Ayers \\ Texas Tech University \\ Paxton R. Payton \\ United States Department of Agriculture-Agricultural Research Service, paxton.payton@ars.usda.gov \\ Naveen Puppala \\ New Mexico State University, npuppala@nmsu.edu
}

See next page for additional authors

Follow this and additional works at: https://digitalcommons.unl.edu/agronomyfacpub

Part of the Agricultural Science Commons, Agriculture Commons, Agronomy and Crop Sciences Commons, Botany Commons, Horticulture Commons, Other Plant Sciences Commons, and the Plant Biology Commons

Belamkar, Vikas; Gomez Selvaraj, Michael; Ayers, Jamie L.; Payton, Paxton R.; Puppala, Naveen; and Burow, Mark D., "A First Insight into Population Structure and Linkage Disequilibrium in the U.S. Peanut Minicore Collection" (2011). Agronomy \& Horticulture -- Faculty Publications. 1001.

https://digitalcommons.unl.edu/agronomyfacpub/1001

This Article is brought to you for free and open access by the Agronomy and Horticulture Department at DigitalCommons@University of Nebraska - Lincoln. It has been accepted for inclusion in Agronomy \& Horticulture -Faculty Publications by an authorized administrator of DigitalCommons@University of Nebraska - Lincoln. 


\section{Authors}

Vikas Belamkar, Michael Gomez Selvaraj, Jamie L. Ayers, Paxton R. Payton, Naveen Puppala, and Mark D. Burow 


\title{
A first insight into population structure and linkage disequilibrium in the US peanut minicore collection
}

\author{
Vikas Belamkar • Michael Gomez Selvaraj • \\ Jamie L. Ayers · Paxton R. Payton • \\ Naveen Puppala $\cdot$ Mark D. Burow
}

Received: 24 June 2010/Accepted: 25 January 2011/Published online: 27 March 2011

(C) Springer Science+Business Media B.V. 2011

\begin{abstract}
Knowledge of genetic diversity, population structure, and degree of linkage disequilibrium (LD) in target association mapping populations is of great importance and is a prerequisite for LD-based mapping. In the present study, 96 genotypes comprising 92 accessions of the US peanut minicore collection, a component line of the tetraploid variety Florunner, diploid progenitors A. duranensis (AA) and A. ipaënsis (BB), and synthetic amphidiploid accession TxAG-6 were investigated with 392 simple sequence repeat (SSR) marker bands amplified using 32
\end{abstract}

Vikas Belamkar-This work was performed in partial fulfillment of the requirements for the Master of Science degree.

\section{Belamkar}

Center for Biotechnology and Genomics, Texas Tech University, Lubbock, TX 79409, USA

V. Belamkar · J. L. Ayers · M. D. Burow $(\bowtie)$

Department of Plant and Soil Science, Texas Tech University, Lubbock, TX 79409, USA

e-mail: mburow@tamu.edu

M. G. Selvaraj · J. L. Ayers · M. D. Burow

Texas AgriLife Research, Texas A\&M System, Lubbock, TX 79403, USA

\section{P. R. Payton}

Plant Stress Germplasm Development Unit, USDA-ARS, Lubbock, TX 79415, USA

\section{N. Puppala}

Agricultural Sciences Center, New Mexico State University, Clovis, NM 88001, USA

Present Address:

V. Belamkar

Interdepartmental Genetics Graduate Program, Iowa State

University, Ames, IA 50011, USA highly-polymorphic SSR primer pairs. Both distance- and model-based (Bayesian) cluster analysis revealed the presence of structured diversity. In general, the wild-species accessions and the synthetic amphidiploid grouped separately from most minicore accessions except for COC155, and were eliminated from most subsequent analyses. UPGMA analysis divided the population into four subgroups, two major subgroups representing subspecies fastigiata and hypogaea, a third group containing individuals from each subspecies or possibly of mixed ancestry, and a fourth group, either consisting of COC 155 alone if wild species were excluded, or of COC155, the diploid species, and the synthetic amphidiploid. Modelbased clustering identified four subgroups- one each for fastigiata and hypogaea subspecies, a third consisting of individuals of both subspecies or of mixed ancestry predominantly from Africa or Asia, and a fourth group, consisting of individuals predominantly of var fastigiata, peruviana, and aequatoriana accessions from South America, including COC155. Analysis of molecular variance (AMOVA) revealed statistically-significant $(P<0.0001)$ genetic variance of $16.87 \%$ among subgroups. A total of $4.85 \%$ of SSR marker pairs revealed significant LD (at $\mathrm{r}^{2} \geq 0.1$ ). Of the syntenic marker pairs separated by distances $<10 \mathrm{cM}, 11-20 \mathrm{cM}, 21-50 \mathrm{cM}$, and $>50 \mathrm{cM}$, $19.33,5.19,6.25$ and $5.29 \%$ of marker pairs were found in strong LD $(P \leq 0.01)$, in accord with LD extending to great distances in self pollinated crops. A threshold value of $r^{2}>0.035$ was found to distinguish mean $r^{2}$ values of linkage distance groups statistically from the mean $r^{2}$ values of unlinked markers; LD was found to extend to $10 \mathrm{cM}$ over the entire minicore collection by this criterion. However, there were large differences in $r^{2}$ values among marker pairs even among tightly-linked markers. The implications of these findings with regard to the possibility of using 
association mapping for detection of genome-wide SSR marker-phenotype association are discussed.

Keywords Peanut - Germplasm - Linkage disequilibrium $\cdot$ SSR

\section{Introduction}

Peanut (Arachis hypogaea L.) is the fifth most-important oilseed crop in the world. Peanut is grown in more than 100 countries on six continents of the world (Nwokolo and Smartt 1996). China and India are currently the largest producers, followed by Nigeria and the USA. The crop is a rich source of oil (40-50\%), proteins (20-50\%) and carbohydrates (10-20\%). As a member of the Fabaceae, peanut is capable of utilizing atmospheric nitrogen by symbiotic nitrogen fixation. Thus, in addition to being a food crop, peanut is capable of increasing the fertility of the soil (Pimratch et al. 2004).

Cultivated peanut is a highly selfing tetraploid species, and its origin is thought to be the result of a single hybridization event between two wild species, A. duranensis (A genome) and A. ipaënsis (B genome), giving rise to a wild diploid hybrid, followed by a chromosome duplication event (Kochert et al. 1996). Domestication of this wild allotetraploid is hypothesized to have resulted in the present day cultivated peanut (Arachis hypogaea L.) (Seijo et al. 2007). This cross was successfully re-created, and resulted in fertile tetraploid progeny (Fávero et al. 2006). Cytological studies demonstrated that cultivated peanut and one wild species in section Arachis, A. monticola, are allotetraploid (Krapovickas and Gregory 1994) with $2 \mathrm{n}=4 \mathrm{x} \quad(2 \mathrm{~A}+2 \mathrm{~B})=40$ chromosomes (Husted 1936; Stebbins 1957; Seijo et al. 2004). Archaeological evidence suggested that domestication of cultivated peanut occurred approximately 3,500 years ago (Simpson et al. 2002). This genetic bottleneck in the species coupled with the self-pollinating mating system has resulted in limited molecular level polymorphism and has been a major hindrance to development of genomic resources in peanut. However, it is expected that the selfing nature and the genetic bottleneck would result in high amounts of LD and genome-wide association studies would become feasible with the current minimal genomic resources available to the peanut community.

Germplasm collections are valuable sources of genes for population improvement, as well as for mapping genes/ QTLs (Quantitative Trait Loci) through linkage analysis and/or association mapping (Jannink et al. 2001; Buckler and Thornsberry 2002; Flint-Garcia et al. 2003; Jansen et al. 2003; Rafalski and Morgante 2004). The US peanut minicore collection consists of 112 diverse accessions
(Holbrook and Dong 2005). The minicore has the potential to identify new sources of variation and serve as a good starting point for association mapping and facilitate the detection of rare allelic variations associated with beneficial traits. In addition a larger core collection (Holbrook et al. 1993) containing 831 accessions is available for association mapping and would provide greater statistical power.

A major concern for performing association mapping in elite crop germplasm is the confounding effect of population structure (Melchinger et al. 1994; Barrett and Kidwell 1998; Huang et al. 2002). The presence of distinct subgroups in populations characterized by different allele frequencies can result in spurious associations (Knowler et al. 1988). Both distance- and model-based cluster analyses are performed to investigate the presence of population structure. Distance-based methods calculate a pairwise distance matrix and result in 'non-overlapping' graphical representations, whereas the model-based methods allow each accession to have membership in several different subgroups, with membership coefficients totaling one.

In addition to the detailed knowledge of population structure, the extent of genome-wide LD is another important prerequisite for association mapping. The extent of LD determines the resolution and power of association mapping. Linkage disequilibrium is affected by many factors such as allele frequency, recombination rate, size of the population, mutation, mating system, genetic bottleneck, selection and admixture (Flint-Garcia et al. 2003). Therefore, a thorough understanding of population structure and patterns of LD across the whole genome will be key for designing and carrying out association mapping.

Simple sequence repeat (SSR) markers have been proven to be more efficient in revealing the diversity in cultivated peanut (Mace et al. 2006; Tang et al. 2007; Cuc et al. 2008) than other markers used previously (RAPDs, RFLPs, and AFLPs). To date, no study has been published giving substantial information about the performance of single nucleotide polymorphisms (SNPs) for characterizing diversity and LD in peanut. Thus, SSRs are currently the best available resource for diversity and LD studies in peanut. In the present study, the population structure and the extent of linkage disequilibrium in the US peanut minicore collection is being investigated with SSR markers, and to the best of our knowledge this is the first report giving insight of LD in the peanut genome. The objectives of the present study are: (1) to evaluate the genetic diversity and population structure of the US peanut minicore collection, and (2) characterize linkage disequilibrium in the peanut genome as a first step towards determining the feasibility of performing association mapping in peanut. 


\section{Materials and methods}

Plant material

The present study was based on 96 genotypes, comprised of 92 accessions of the US peanut minicore collection, a subline, UF 439-16-10-3-2, of the US variety Florunner (Norden et al. 1969), probable diploid progenitors Arachis duranensis K7988 and Arachis ipaënsis K30076 (Krapovickas and Gregory 1994; Seijo et al. 2007), and the synthetic amphidiploid TxAG-6 (Simpson et al. 1993) (Table 1). All genotypes used in the study except the diploid progenitors were tetraploids. The US peanut minicore collection consists of 112 accessions (Holbrook and Dong 2005). For facilitating genotyping on standard 96-well plates, 92 accessions representing most of the genetic diversity of US minicore collection were selected for the current study. Results of Kottapalli et al. (2007) provided information on genetic diversity among a subset of minicore accessions and thus facilitated selection of 92 diverse genotypes for the present study. The synthetic amphidiploid TxAG-6 and the subline of the US variety Florunner are parents of a tetraploid linkage map (Burow et al. 2001), which was used as a reference map for determining the position of markers. Diploid progenitors, A. duranensis and A. ipaënsis were included to determine the donor of the alleles in the cultivated tetraploid peanut accessions that would facilitate scoring of codominant SSR markers.

\section{Determination of subspecies and market type of minicore accessions}

Minicore accessions subspecies and market type identities were based initially on data in GRIN (http://www.grinars.usda.gov). Published data were checked against field measurements based on growth of the minicore collection at the Texas Tech University Experimental Farm at Lubbock, TX in 2006. Subspecies, botanical variety, and market class was determined by presence or absence of flowers on the main stem, branch elevation, spreading or erect growth habit, number of seeds per pod, and pod appearance, as used for classification of peanut (IBPGR 1992).

Molecular data

\section{DNA isolation and quantification}

DNA of each accession was extracted from young juvenile leaves using the Plant DNAEasy kit (Qiagen Inc., Valencia, $\mathrm{CA}$ ), as per the manufacturer's protocol. DNA concentrations and purity of the samples were determined using the
Nanodrop ND-1000 spectrophotometer (Nanodrop, Inc., Wilmington, DE). All DNA samples were diluted to $10 \mathrm{ng} \mu \mathrm{l}^{-1}$ with TE buffer $\mathrm{pH}$ 8.0.

\section{SSR primer pairs}

The SSR primer pairs found polymorphic in an ongoing project (Gomez et al. 2008) for enrichment of the RFLPbased tetraploid genetic linkage map of Burow et al. (2001) were utilized in the present study. Additional markers were obtained from Hong et al. (2008) and Foncéka et al. (2009) after creating consensus linkage groups (LGs) using the Comparative Map and Trait Viewer (CMTV) tool version 1.1 (Sawkins et al. 2004). A total of 32 primer pairs were successfully scored on all the 96 genotypes used in the present study (Table 2). The 32 primer pairs amplified a total of 392 SSR marker bands and covered a total of about $500 \mathrm{cM}$ distance of the genetic linkage map, which is close to $25 \%$ of the peanut genome based on Burow et al. (2001) and Foncéka et al. (2009). The consensus LG2 and LG8 had 8 and 4 primers each, LG3, LG4, LG6, LG7 and LG11 had 3 primers each, LG1, LG9, LG10 and LG13 had one primer each, and 3 unmapped primers were used (Table 2). The primers used in the study were obtained from different sources as listed, AH series (Hopkins et al. 1999), PGP series (Ferguson et al. 2004a), PGS series (Ferguson et al. 2004b), PM series (He et al. 2003), RN17F12, ML1G04, Seq2H11, TC series, and gi-series (Moretzsohn et al. 2005), PMc series (He et al. 2005), and Ap series (Palmieri et al. 2002; Palmieri et al. 2005).

\section{Molecular genotyping}

PCR amplifications were carried out using the three-primer system incorporating a fluorescent dye-labeled primer. Reactions were performed in $10 \mu \mathrm{l}$ volumes containing $1 \mu \mathrm{l}$ 10x PCR buffer II (Applied Biosystems, Foster City, CA), $0.8 \mu \mathrm{l} 25 \mathrm{mM} \mathrm{MgCl}_{2}, 1.25 \mu \mathrm{l}$ dNTPs (2 mM each), $0.5 \mu \mathrm{l}$ each forward and 5'-M13 reverse-tagged reverse primer (IDT Inc., Coralville, IA) at $10 \mu \mathrm{M}$ each, $2,1.25$ or $0.5 \mu \mathrm{l}$ of one M13 reverse primer 5'-GACGTTGTAAAACGA CGGCC-3' which was $5^{\prime}$-labeled with D2, D3 or D4 fluorescent dyes respectively $(4,2.5,1 \mathrm{pmol}), 0.1 \mu \mathrm{l}$ of AmpliTaq DNA polymerase ( $5 \mathrm{U} / \mu \mathrm{l})$ (Applied Biosystems, Inc.), and $20 \mathrm{ng}$ of genomic DNA. PCR amplifications were performed in PTC-200 and PTC-100 thermal cyclers (BioRad, Hercules, CA) following a touchdown strategy: initial denaturation at $94^{\circ} \mathrm{C}$ for $3 \mathrm{~min}$; followed by 19 cycles of $94^{\circ} \mathrm{C}$ for $30 \mathrm{~s}, 63^{\circ} \mathrm{C}$ for $30 \mathrm{~s}$ (decreasing $0.5^{\circ} \mathrm{C}$ per cycle), $72^{\circ} \mathrm{C}$ for $1 \mathrm{~min} ; 19$ cycles of $94^{\circ} \mathrm{C}$ for $15 \mathrm{~s}, 55^{\circ} \mathrm{C}$ for $30 \mathrm{~s}$, $72^{\circ} \mathrm{C}$ for $1 \mathrm{~min}$; and a final extension at $72^{\circ} \mathrm{C}$ for $10 \mathrm{~min}$. Polymorphisms among accessions at amplified microsatellite loci were detected on a Beckman Coulter CEQ 8000 
Table 1 Description of peanut accessions used in the study

\begin{tabular}{|c|c|c|c|c|c|}
\hline $\begin{array}{l}\text { Core collection } \\
\text { No. }\end{array}$ & PI No. & $\begin{array}{l}\text { Country } \\
\text { of origin }\end{array}$ & $\begin{array}{l}\text { Subspecies and botanical } \\
\text { variety }\end{array}$ & Ploidy & Market type \\
\hline COC008 & 295730 & India & ND & $4 \mathrm{x}$ & ND \\
\hline COC016 & 493356 & Paraguay & ND & $4 \mathrm{x}$ & ND \\
\hline $\mathrm{COC} 033$ & 493547 & Brazil & fastigiata var fastigiata & $4 \mathrm{x}$ & Valencia \\
\hline COC041 & 493631 & Paraguay & fastigiata var fastigiata & $4 \mathrm{x}$ & Valencia \\
\hline $\mathrm{COC} 050$ & 493717 & Paraguay & fastigiata var fastigiata & $4 \mathrm{x}$ & Valencia \\
\hline COC053 & 493729 & Paraguay & fastigiata var fastigiata & $4 \mathrm{x}$ & Valencia \\
\hline COC068 & 493880 & Paraguay & fastigiata var fastigiata & $4 \mathrm{x}$ & Valencia \\
\hline COC075 & 493938 & Paraguay & fastigiata var ND & $4 \mathrm{x}$ & ND \\
\hline COC080 & 494018 & Brazil & fastigiata var ND & $4 \mathrm{x}$ & ND \\
\hline COC082 & 494034 & Paraguay & fastigiata var ND & $4 \mathrm{x}$ & ND \\
\hline COC087 & 475863 & Bolivia & fastigiata var ND & $4 \mathrm{x}$ & ND \\
\hline COC092 & 497318 & Bolivia & $\mathrm{ND}$ & $4 \mathrm{x}$ & ND \\
\hline COC097 & 497395 & Bolivia & ND & $4 \mathrm{x}$ & ND \\
\hline COC112 & 497517 & Brazil & fastigiata var fastigiata & $4 \mathrm{x}$ & Valencia \\
\hline COC115 & 496401 & Burkina Faso & hypogaea var hypogaea & $4 \mathrm{x}$ & Virginia \\
\hline COC119 & 496448 & Burkina Faso & hypogaea var hypogaea & $4 \mathrm{x}$ & Virginia \\
\hline COC125 & 504614 & Colombia & fastigiata var vulgaris & $4 \mathrm{x}$ & Spanish \\
\hline COC132 & 497639 & Ecuador & fastigiata var fastigiata & $4 \mathrm{x}$ & Valencia \\
\hline COC149 & 502040 & Peru & fastigiata var vulgaris & $4 \mathrm{x}$ & Spanish \\
\hline COC155 & 502111 & Peru & fastigiata var fastigiata & $4 \mathrm{x}$ & Valencia \\
\hline COC157 & 502120 & Peru & fastigiata var fastigiata & $4 \mathrm{x}$ & Valencia \\
\hline COC166 & 494795 & Zambia & hypogaea var hypogaea & $4 \mathrm{x}$ & runner \\
\hline COC187 & 331314 & Argentina & hypogaea var hypogaea & $4 \mathrm{x}$ & Virginia \\
\hline COC202 & 331297 & Argentina & ND & $4 \mathrm{x}$ & ND \\
\hline COC208 & 274193 & Bolivia & hypogaea var hypogaea & $4 \mathrm{x}$ & Virginia \\
\hline COC223 & 290620 & Argentina & hypogaea var hypogaea & $4 \mathrm{x}$ & Virginia \\
\hline COC227 & 290566 & India & hypogaea var hypogaea & $4 \mathrm{x}$ & runner \\
\hline COC 230 & 290594 & India & hypogaea var hypogaea & $4 \mathrm{x}$ & ND \\
\hline COC246 & 343398 & Israel & hypogaea var hypogaea & $4 \mathrm{x}$ & Virginia \\
\hline COC249 & 343384 & Israel & ND & $4 \mathrm{x}$ & ND \\
\hline COC266 & 200441 & Japan & fastigiata var vulgaris & $4 \mathrm{x}$ & Spanish \\
\hline $\mathrm{COC} 270$ & 196635 & Madagascar & hypogaea var hypogaea & $4 \mathrm{x}$ & runner \\
\hline COC277 & 259851 & Malawi & hypogaea var hypogaea & $4 \mathrm{x}$ & Virginia \\
\hline COC 287 & 355271 & Mexico & hypogaea var hypogaea & $4 \mathrm{x}$ & runner \\
\hline COC296 & 399581 & Nigeria & hypogaea var hypogaea & $4 \mathrm{x}$ & Virginia \\
\hline COC310 & 337406 & Paraguay & hypogaea var hypogaea & $4 \mathrm{x}$ & ND \\
\hline COC334 & 159786 & Senegal & fastigiata var ND & $4 \mathrm{x}$ & ND \\
\hline COC338 & 268696 & South Africa & ND & $4 \mathrm{x}$ & ND \\
\hline COC342 & 298854 & South Africa & ND & $4 \mathrm{x}$ & ND \\
\hline COC367 & 268868 & Sudan & hypogaea var hypogaea & $4 \mathrm{x}$ & Virginia \\
\hline COC381 & 313129 & Taiwan & ND & $4 \mathrm{x}$ & ND \\
\hline COC384 & 155107 & Uruguay & fastigiata var fastigiata & $4 \mathrm{x}$ & Valencia \\
\hline COC388 & 162655 & Uruguay & fastigiata var ND & $4 \mathrm{x}$ & $\mathrm{ND}$ \\
\hline COC406 & 152146 & Uruguay & fastigiata var fastigiata & $4 \mathrm{x}$ & Valencia \\
\hline COC431 & 337293 & Brazil & fastigiata var fastigiata & $4 \mathrm{x}$ & Valencia \\
\hline COC433 & 270907 & Zambia & ND & $4 \mathrm{x}$ & $\mathrm{ND}$ \\
\hline COC446 & 270905 & Zambia & ND & $4 \mathrm{x}$ & ND \\
\hline COC458 & 268996 & Zambia & hypogaea var ND & $4 \mathrm{x}$ & ND \\
\hline COC468 & 270998 & Zambia & $\mathrm{ND}$ & $4 \mathrm{x}$ & ND \\
\hline
\end{tabular}


Table 1 continued

\begin{tabular}{|c|c|c|c|c|c|c|}
\hline & No. & & of origin & variety & & \\
\hline & COC477 & 268806 & Zambia & fastigiata var vulgaris & $4 \mathrm{x}$ & Spanish \\
\hline & COC481 & 268755 & Zambia & fastigiata var ND & $4 \mathrm{x}$ & ND \\
\hline & COC485 & 270786 & Zambia & fastigiata var ND & $4 \mathrm{x}$ & ND \\
\hline & COC488 & 356004 & Argentina & fastigiata var fastigiata & $4 \mathrm{x}$ & Valencia \\
\hline & COC506 & 259658 & Cuba & hypogaea var hypogaea & $4 \mathrm{x}$ & runner \\
\hline & COC516 & 288146 & India & ND & $4 \mathrm{x}$ & ND \\
\hline & COC526 & 288210 & India & ND & $4 \mathrm{x}$ & ND \\
\hline & COC534 & 296550 & Israel & ND & $4 \mathrm{x}$ & ND \\
\hline & COC535 & 296558 & Israel & hypogaea var ND & $4 \mathrm{x}$ & ND \\
\hline & COC540 & 295250 & Israel & hypogaea var hypogaea & $4 \mathrm{x}$ & Virginia \\
\hline & COC541 & 295309 & Israel & hypogaea var ND & $4 \mathrm{x}$ & ND \\
\hline & COC542 & 370331 & Israel & hypogaea var hypogaea & $4 \mathrm{x}$ & Virginia \\
\hline & COC546 & 259836 & Malawi & fastigiata var vulgaris & $4 \mathrm{x}$ & Spanish \\
\hline & COC552 & 338338 & Venezuela & ND & $4 \mathrm{x}$ & $\mathrm{ND}$ \\
\hline & COC553 & 157542 & China & hypogaea var hypogaea & $4 \mathrm{x}$ & Virginia \\
\hline & COC559 & 158854 & China & fastigiata var fastigiata & $4 \mathrm{x}$ & Valencia \\
\hline & COC579 & 271019 & Zambia & fastigiata var ND & $4 \mathrm{x}$ & ND \\
\hline & COC580 & 268586 & Zambia & ND & $4 \mathrm{x}$ & ND \\
\hline & COC588 & 403813 & Argentina & fastigiata var ND & $4 \mathrm{x}$ & ND \\
\hline & COC605 & 475918 & Bolivia & fastigiata var ND & $4 \mathrm{x}$ & ND \\
\hline & COC610 & 475931 & Bolivia & ND & $4 \mathrm{x}$ & ND \\
\hline & COC631 & 408743 & Brazil & fastigiata var vulgaris & $4 \mathrm{x}$ & Spanish \\
\hline & COC643 & 433347 & China & fastigiata var vulgaris & $4 \mathrm{x}$ & Spanish \\
\hline & COC650 & 478819 & India & fastigiata var vulgaris & $4 \mathrm{x}$ & Spanish \\
\hline & COC678 & 476636 & Nigeria & hypogaea var hypogaea & $4 \mathrm{x}$ & runner \\
\hline & COC698 & 372305 & Nigeria & hypogaea var hypogaea & $4 \mathrm{x}$ & Virginia \\
\hline & COC703 & 476432 & Nigeria & fastigiata var vulgaris & $4 \mathrm{x}$ & Spanish \\
\hline & COC711 & 476025 & Peru & fastigiata var fastigiata & $4 \mathrm{x}$ & Valencia \\
\hline & COC725 & 240560 & South Africa & fastigiata var fastigiata & $4 \mathrm{x}$ & Valencia \\
\hline & COC728 & 292950 & South Africa & hypogaea var hypogaea & $4 \mathrm{x}$ & runner \\
\hline & COC731 & 162857 & Sudan & hypogaea var hypogaea & $4 \mathrm{x}$ & Virginia \\
\hline & COC740 & 407667 & Thailand & fastigiata var vulgaris & $4 \mathrm{x}$ & Spanish \\
\hline $\begin{array}{l}\text { Data on country of origin was } \\
\text { obtained from GRIN }\end{array}$ & $\mathrm{COC} 747$ & 478850 & Uganda & fastigiata var ND & $4 \mathrm{x}$ & ND \\
\hline (http://www.ars-grin.gov/ & COC755 & 482189 & Zimbabwe & fastigiata var fastigiata & $4 \mathrm{x}$ & Valencia \\
\hline npgs/searchgrin.html), whereas & COC760 & 471952 & Zimbabwe & fastigiata var vulgaris & $4 \mathrm{x}$ & Spanish \\
\hline information on subspecies, & COC763 & 442768 & Zimbabwe & hypogaea var hypogaea & $4 \mathrm{x}$ & Virginia \\
\hline type is a consensus (where such & COC775 & 482120 & Zimbabwe & fastigiata var fastigiata & $4 \mathrm{x}$ & Valencia \\
\hline exists) based on data in GRIN & COC781 & 471954 & Zimbabwe & fastigiata var fastigiata & $4 \mathrm{x}$ & Valencia \\
\hline and from field observations in & COC787 & 429420 & Zimbabwe & fastigiata var fastigiata & $4 \mathrm{x}$ & Valencia \\
\hline $\begin{array}{l}2006 \text { (M. Burow and N. Pup- } \\
\text { pala. unpublished data) }\end{array}$ & COC796 & 468271 & Bolivia & hypogaea var ND & $4 \mathrm{x}$ & ND \\
\hline$N D$ Not determined (uncertain). & COC798 & 461434 & China & fastigiata var vulgaris & $4 \mathrm{x}$ & Spanish \\
\hline A comparison of data from & COC802 & 196622 & Ivory Coast & hypogaea var hypogaea & $4 \mathrm{x}$ & Virginia \\
\hline GRIN and field measurements & $\mathrm{COC} 805$ & 355268 & Mexico & hypogaea var hypogaea & $4 \mathrm{x}$ & runner \\
\hline in Texas and New Mexico gave & Florunner & 565448 & USA & hypogaea var hypogaea & $4 \mathrm{x}$ & runner \\
\hline
\end{tabular}

Genetic Analysis System. The use of three different dyes facilitated multiplexing of samples during separation and allele sizing. Pooled products were then dialyzed on a $0.025 \mu \mathrm{m}$ nitrocellulose membrane filter (Millipore Inc.,
Billerica, MA) laid over $18 \mathrm{M} \Omega \mathrm{cm}^{-1}$ water for $30 \mathrm{~min}$. Each multiplexed sample was separated on the CEQ-8000 using the standard Frag-1 method (for 400-bp size standard) or Frag-2 method (for 600-bp size standard). Fragments 
Table 2 Details of SSR primers used for genotypic analysis, and the location to which they were mapped

\begin{tabular}{|c|c|c|c|c|c|c|c|c|}
\hline LG & $\begin{array}{l}\text { Coverage } \\
\mathrm{cM}\end{array}$ & $\begin{array}{l}\text { No. of primer } \\
\text { pairs }\end{array}$ & $\begin{array}{l}\text { Name of primer } \\
\text { pairs }\end{array}$ & $\begin{array}{l}\text { No. of } \\
\text { bands }\end{array}$ & $\begin{array}{l}\text { PIC } \\
\text { Range }\end{array}$ & $\begin{array}{l}\text { PIC } \\
\text { Mean }\end{array}$ & $\begin{array}{l}\text { No. of bands with } \\
\text { frequency }<5 \%\end{array}$ & $\begin{array}{l}\text { No. of genotype- } \\
\text { specific bands }\end{array}$ \\
\hline \multirow[t]{8}{*}{$2^{a}$} & \multirow[t]{8}{*}{201} & \multirow[t]{8}{*}{8} & RN17F12 & 9 & $0.02-0.33$ & 0.17 & 2 & 1 \\
\hline & & & Seq2H11 & 4 & $0.02-0.21$ & 0.11 & 2 & 1 \\
\hline & & & TC2D06 & 24 & $0.02-0.29$ & 0.07 & 19 & 12 \\
\hline & & & Seq2D01 & 8 & $0.02-0.30$ & 0.12 & 4 & 2 \\
\hline & & & AH193 & 24 & $0.02-0.32$ & 0.07 & 18 & 15 \\
\hline & & & ТC4H02 & 8 & $0.02-0.34$ & 0.16 & 4 & 1 \\
\hline & & & Seq3E05 & 5 & $0.02-0.37$ & 0.20 & 2 & 1 \\
\hline & & & gi-0919 & 6 & $0.02-0.34$ & 0.21 & 2 & 1 \\
\hline \multirow[t]{4}{*}{$8^{a}$} & \multirow[t]{4}{*}{70} & \multirow[t]{4}{*}{4} & TC1E06 & 17 & $0.02-0.37$ & 0.08 & 13 & 6 \\
\hline & & & PM42 & 7 & $0.02-0.37$ & 0.19 & 4 & 2 \\
\hline & & & PM238 & 18 & $0.03-0.35$ & 0.13 & 9 & 6 \\
\hline & & & TC2A02 & 24 & $0.02-0.36$ & 0.10 & 14 & 10 \\
\hline \multirow[t]{2}{*}{4} & \multirow[t]{2}{*}{67.8} & \multirow[t]{2}{*}{3} & PM36 & 8 & $0.03-0.37$ & 0.15 & 4 & 3 \\
\hline & & & PM204 & 17 & $0.02-0.25$ & 0.10 & 9 & 4 \\
\hline \multirow[t]{3}{*}{6} & \multirow[t]{3}{*}{61.5} & \multirow[t]{3}{*}{3} & PGS11G03 & 23 & $0.03-0.37$ & 0.12 & 13 & 9 \\
\hline & & & PGS10C12 & 9 & $0.03-0.37$ & 0.15 & 4 & 3 \\
\hline & & & PGP07B09 & 9 & $0.02-0.37$ & 0.17 & 3 & 3 \\
\hline \multirow[t]{3}{*}{7} & \multirow[t]{3}{*}{46.6} & \multirow[t]{3}{*}{3} & PM32 & 7 & $0.02-0.37$ & 0.18 & 4 & 1 \\
\hline & & & PGP08D09 & 25 & $0.02-0.37$ & 0.11 & 16 & 9 \\
\hline & & & TC5A06 & 31 & $0.02-0.21$ & 0.06 & 24 & 17 \\
\hline \multirow[t]{2}{*}{3} & \multirow[t]{2}{*}{39} & \multirow[t]{2}{*}{3} & AH229 & 2 & $0.02-0.02$ & 0.02 & 2 & 2 \\
\hline & & & TC7G10 & 24 & $0.02-0.36$ & 0.06 & 19 & 20 \\
\hline \multirow[t]{3}{*}{11} & \multirow[t]{3}{*}{17.3} & \multirow[t]{3}{*}{3} & ТС2C07 & 27 & $0.02-0.36$ & 0.08 & 20 & 16 \\
\hline & & & PM201 & 4 & $0.02-0.35$ & 0.16 & 2 & 2 \\
\hline & & & TC11B11 & 4 & $0.02-0.10$ & 0.05 & 3 & 1 \\
\hline 1 & & 1 & PM145 & 3 & $0.15-0.34$ & 0.26 & 0 & 3 \\
\hline 9 & & 1 & TC3A12 & 7 & $0.02-0.37$ & 0.14 & 4 & 4 \\
\hline 10 & & 1 & PMc99 & 7 & $0.02-0.37$ & 0.17 & 2 & 1 \\
\hline 13 & & 1 & PMc348 & 4 & $0.02-0.37$ & 0.20 & 2 & 1 \\
\hline \multirow[t]{2}{*}{ Unmapped } & & 3 & TC1H04 & 8 & $0.02-0.19$ & 0.05 & 7 & 6 \\
\hline & & & ML1G04 & 7 & $0.03-0.36$ & 0.13 & 3 & 3 \\
\hline 3,4 and unmapped & - & - & gi-909 & 12 & $0.02-0.36$ & 0.15 & 6 & 2 \\
\hline Total & 503.2 & $34^{\#}(32)$ & & & & & & \\
\hline
\end{tabular}

\# List of SSR primers pairs screened is 32 (in parenthesis). Primer gi-909 detected three loci. Loci 1 and 2 were mapped on two different LGs and 3 was unmapped. Thus, the total number of loci screened is higher (34)

${ }^{a}$ LG2 and LG8 are consensus LGs that were developed by comparative mapping

were sized using the default fragment analysis protocol with the mobility correction factor of PA Ver1 and the size calling of amplified fragments was performed visually, so as to have minimal errors in sizing the amplified product.

Data analysis

\section{Scoring of SSR marker data}

The SSR markers in the current study were scored as dominant markers, considering each band as a separate marker locus. SSR markers are generally codominant and have the power to detect heterozygotes, but assigning incorrect allelic relationships would lead to serious errors in LD analysis (Sand 2007). The US peanut minicore collection contains accessions with unknown ancestry and, moreover, because peanut is an allotetraploid crop, there is a substantial risk of errors in allele calling where multiple bands may be amplified from homoeologous chromosomes. Thus, SSR products were scored as present or absent; ' 1 ' for present and ' 0 ' for absent, or ' 2 ' for present and ' 1 ' for absent, and missing values were represented as 
' -9 ', or '?' or '9', depending on the software used. Although, the use of dominant markers as compared to the codominant markers results in reduced statistical power due to missing heterozygote information ( $\mathrm{Li}$ et al. 2007), this was deemed necessary to avoid errors due to incorrect assignment of allelic relationships. Successful implementation of linkage disequilibrium analysis using dominant scoring has been reported by several authors including Abdurakhmonov et al. (2009), Breseghello and Sorrells (2006) and Tommasini et al. (2007).

\section{Molecular diversity and phylogenetic analysis}

Distance-based cluster analysis was performed using NTSYS PC ver 2.0 (Rohlf 2000). The pairwise distance matrix was computed based on the DICE similarity coefficient (Sokal and Sneath 1963) using the SIMEQUAL routine. Similarity coefficients were used to construct the Unweighted Pair Group Method with Arithmetic Average (UPGMA) dendrogram (Sokal and Michener 1958), using Sequential Agglomerative Hierarchical and Nested (SAHN) clustering (Sneath and Sokal 1973), and a tree was displayed using the graphics capabilities of the program. A cophenetic matrix was derived from the similarity matrix using the COPH (cophenetic values) program and the goodness of fit of the clusters was tested by comparing the original similarity matrix with the cophenetic value matrices using the Mantel matrix correspondence test (Mantel 1967) in the MXCOMP program. The phylogenetic tree was further confirmed by 1,000 bootstrap resamplings using PowerMarker Ver 3.25 software package (Liu and Muse 2005).

Principal coordinate analysis (PCoA) was performed using the DCENTER and EIGEN programs described by Gower (1966) in NTSYS PC. Distance-based cluster analysis and PCoA were performed both including and excluding the wild species and TxAG-6. Gene diversity and the polymorphism information content (PIC) values were estimated using the PowerMarker Ver 3.25 software package. The PIC value is defined as $1-\Sigma p_{i}^{2}$, where $p_{i}$ is the frequency of the ith allele in the population.

\section{Model based population structure analysis}

The genetic structure of the population was also investigated using the model-based (Bayesian) clustering method implemented in the software package STRUCTURE Ver 2.3.2 (Pritchard et al. 2000). The genotypes were coded using a two-row format: $x_{i, j}^{1}, x_{i, j}^{2}$, in which $i$ represents individual at locus $j$ as described by Pritchard et al. (2007) and the SSR markers were coded as dominant $(1,-9 ; 2,-9)$ (see Abdurakhmonov et al. 2009). Five independent runs of the program were carried out for a ' $\mathrm{K}$ ' value ranging from
1 to 10 , with 50,000 burn-in time and 100,000 iterations, assuming an admixture model with correlated allele frequencies (Falush et al. 2003; Pritchard and Wen 2004; Falush et al. 2007). Further, the program was also run ten times for each ' $\mathrm{K}$ ' value, ranging from 1 to 10 , using the admixture model with correlated allele frequencies, with 20,000 replicates for burn-in and 10,000 replicates during analysis (Wang et al. 2009). Values of k were also tested using methods in Evanno et al. (2005). Analyses were also carried out both including and excluding the wild species and TxAG-6.

\section{Population differentiation in the US minicore collection}

Analysis of molecular variance (AMOVA) was performed using ARLEQUIN Ver 3.1 (Excoffier et al. 2005) to test the significance of genetic variance within and among three subgroups (Weir and Cockerham 1984; Excoffier et al. 1992; Weir 1996) identified in the US peanut minicore collection by the model-based clustering (Bayesian) method. Because of the smaller size of the fourth subgroup, this subgroup was excluded from the population differentiation analysis. The population subgroup-specific $F_{S T}$, which explains the variance in the subgroups relative to the total population (Weir and Hill 2002), and the pairwise $F_{S T}$, which provides estimates of genetic distances between the population subgroups, were also estimated (Reynolds et al. 1983).

Genetic variances within and among subgroups were further confirmed by a Bayesian approach implemented in the software package Hickory ver 1.1 (Holsinger and Lewis 2003). This package was used because SSR markers in the present study were scored as dominant markers, and the software package provides estimates of variances within and among population subgroups from dominant markers without prior knowledge of inbreeding history (Holsinger et al. 2002). Several runs of full, $f=0$, theta $=0$ and $\mathrm{f}=$ free models were performed with the following sampling parameters: burnin $=50,000$, sample $=250,000$, and thin $=50$, as per Holsinger and Lewis (2003).

\section{Linkage disequilibrium}

Linkage disequilibrium estimates and the significance of pairwise comparisons between SSR marker pairs were performed according to Whitt and Buckler (2003) using the software package Trait Analysis by aSSociation, Evolution and Linkage (TASSEL) Ver 2.1 (http://www.maizegene tics.net/bioinformatics). Linkage disequilibrium was evaluated using the minicore subset plus checks, and also within the selected subgroups identified by the modelbased clustering algorithm. Linkage disequilibrium analysis excluding the two diploid wild species and TxAG- 6 was 
also performed, and the results were similar (data not shown). Of the total 392 SSR markers amplified, 150 were used for estimating genome-wide LD between all pairs of SSR markers. The reduction in the total number of markers was due to the entire data set being filtered to eliminate markers with a frequency less than $5 \%$. This was done because rare markers inflate LD estimates, in particular the statistical significance ( $P$-values) (Mohlke et al. 2001; McRae et al. 2002). The removal of minor markers was performed using the TASSEL 'Sites' filtration function. The LD parameters $r^{2}$ and $D^{\prime}$ were estimated and plots of $r^{2}$ as a function of genetic distance were drawn. The comparison-wise significance ( $P$-values) of SSR marker pairs was determined by performing 100,000 permutations.

The threshold for LD decay was empirically estimated in the entire population and the fastigiata subgroup based on using the $\mathrm{r}^{2}$ values of unlinked markers as a background LD estimate, as per Mather et al. (2007). However, instead of using the $\mathrm{r}^{2}$ value corresponding to the 75 th percentile, the mean $r^{2}$ of the group was used, and then a pooled standard error of the mean of the $\mathrm{r}^{2}$ value of this group and of marker pair groups at $0,5,10,15,20,25$, and $30 \mathrm{cM}$ was constructed assuming unequal error variances and multiplied by 1.96 and added to the mean $r^{2}$ of the unlinked marker group. Thus, distance-based groups of markers with mean $r^{2}$ greater than the calculated threshold $r^{2}$ value can be stated to have a $95 \%$ probability or greater of having a mean LD value greater than that of the set of unlinked markers.

Linkage disequilibrium decay curves were calculated using PsiPlot (Poly Software International, Pearl River, NY) using the exponential decay 2 curve fitting function. The extent of LD was estimated as the point where the fitted curve intersected the threshold line.

\section{Results}

\section{SSR summary statistics}

A total of 392 SSR marker bands were amplified and scored from 32 SSR primer pairs in the 96 genotypes. The average number of bands per primer pair was 12.3 (ranging from 2 to 31). The high average number of bands per primer pair observed was due to the large number of unique bands produced by diploid progenitors, A. duranensis and A. ipaënsis, and the amphidiploid TxAG-6. The polymorphism information content for the SSR primer pairs was in the range of 0.02 to 0.38 with an average of 0.11 . The diversity index ranged from 0.02 to 0.50 , with an average of 0.13. Additional details, for each primer pair are provided in Table 2. The filtering of the SSR data for 5\% minor allele frequency generated a data set containing 150 marker bands, covering about $500 \mathrm{cM}$ distance on the genetic linkage map.

The most probable diploid progenitors, A. duranensis and A. ipaënsis, amplified 52.78 and $42.86 \%$ bands which were not present in any of the minicore accessions. Hence, it was often impossible to assign the genomic origin to the amplified band. Therefore, SSR primers were scored as dominant markers (present/absent) to avoid assigning incorrect allelic relationship to the amplified alleles in case of cultivated tetraploid minicore accessions (see Sand 2007; Abdurakhmonov et al. 2009).

Distance and model-based (Bayesian) diversity analysis

Among the 96 genotypes investigated, the distance-based diversity analysis identified four main subclusters in the population. The diploid progenitors, A. duranensis and $A$. ipaënsis, and the amphidiploid TxAG-6 had little genetic similarity to the US minicore accessions, and clustered separately from the rest of the accessions with the exception of COC155; the analysis was rerun without these three accessions, with little difference, except that subcluster D was reduced to the one accession COC155 (Fig. 1). The clustering of the US minicore accessions was mainly based on the subspecies hypogaea and fastigiata. The minicore accessions of the subspecies hypogaea formed a clear separate subcluster (A) that consisted of 42 accessions comprising 25 hypogaea varieties, plus 14 accessions the subspecies identity of which were uncertain based on differences in the observations in GRIN and at the Texas Tech University Farm (will be further referred as 'uncertain'), and 3 fastigiata genotypes (COC132, 149 and 157). Hence, the subcluster A was termed as hypogaea subcluster. Subcluster B represented primarily the fastigiata subspecies and was made up of 32 accessions, of which 29 were confirmed as fastigiata, 2 were of uncertain subspecies classification, and 1 was hypogaea (COC542). The fastigiata subcluster could be further split into two subgroups B1 and B2. The B1 subgroup contained only Valencia type genotypes whereas subgroup B2 had a mix of Valencia and Spanish market types. The third subcluster, C, was made up of 18 accessions consisting of 11 fastigiata genotypes, 4 hypogaea genotypes, 2 accessions of uncertain subspecies classification, and a component line of the US variety Florunner. This subcluster was named "mixed". It was further subdivided into subgroups $\mathrm{C} 1$ and $\mathrm{C} 2$; subgroup $\mathrm{C} 2$ contained what, after further field evaluation in 2010, appear to be four subsp. fastigiata var. fastigiata and two subsp. fastigiata var. peruviana accessions (COC552, and COC747). A cophenetic value matrix was generated from the coefficients of SAHN's cluster analysis of the similarity matrix. The correlation between the genetic distance and the cophenetic matrix was highly significant with an $r$ value 
Fig. 1 UPGMA dendrogram describing the pattern of genetic diversity among the 92 peanut minicore genotypes plus Florunner. The numbers at the right of the tree indicate the core collection number. The capital letters illustrate the four main subclusters. A hypogaea subcluster, $B$ fastigiata subcluster, B1 Valencia subgroup, $B 2$ Spanish and Valencia subgroup, $C$ Mixed subcluster, $D$ COC155

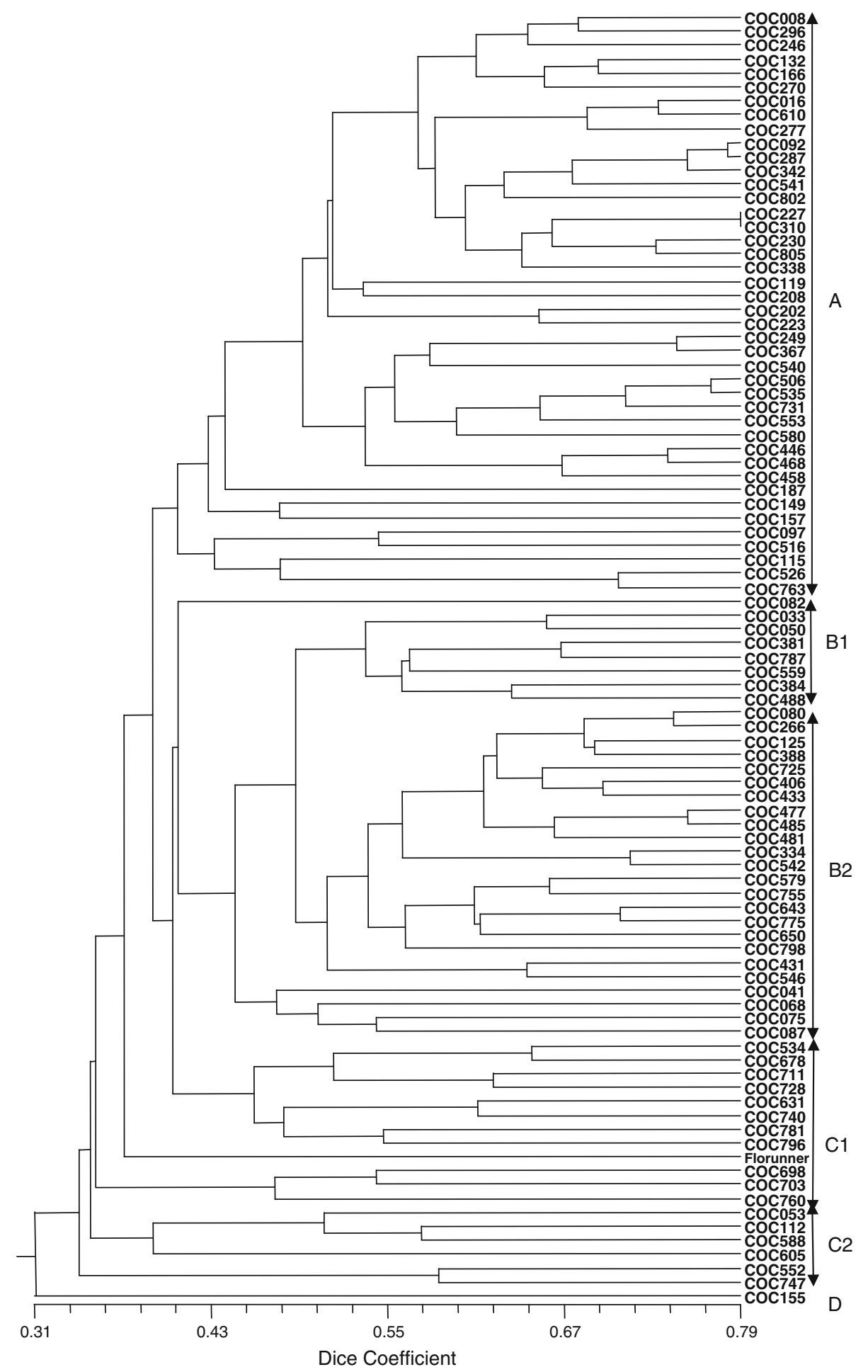

of 0.76, which indicated that the UPGMA dendrogram was a good fit to the matrix.

Model-based (Bayesian) diversity analysis also identified four groups in the population. The Bayesian posterior probability peaked at $\mathrm{K}=4$, three times in five independent runs of the program STRUCTURE. The difference between the posterior probabilities at $\mathrm{K}=4$ and $\mathrm{K}=5$ was about 5,000, confirming the value as $\mathrm{K}=4$ as per the documentation of STRUCTURE ver 2.3 (Pritchard and Wen 2004). Further confirmation was obtained when STRUCTURE was run ten times for each $\mathrm{K}$ value and the run showing the highest posterior probability was recorded. The highest Bayesian posterior probability steadily increased from $K=4$ to $K=7$, and decreased thereafter. 
However, the highest number of accessions assigned to a specific group with a probability higher than $50 \%$ was obtained with $\mathrm{K}=4$ (72 accessions, i.e., $75 \%$ of the total), while for $\mathrm{K}=5,6$ and 7, this percentage dropped to 62.5 , 64.6 and $67.7 \%$ respectively. The results were also confirmed with an ad hoc criterion described by Evanno et al. (2005). With wild species present, this clearly determined $\mathrm{K}=4$. With wild species absent, the average posterior probability of ten runs peaked at $\mathrm{K}=4$, and in the plot of ad hoc criterion (Evanno et al. 2005) versus K, a peak was observed at $K=3$ and 4 . Hence, the value of $K$ with the absence of wild species and TxAG-6 was deduced as 4, in accord with the UPGMA and the PCoA results.

The four groups (G1 to G4, Fig. 2a) identified by the model-based clustering in the population (without wild species and TxAG-6) had a sensible biological interpretation. Group G2 mainly consisted of accessions representing the hypogaea subspecies. The group consisted of 20 hypogaea accessions, 10 accessions of uncertain subspecies identity, and two fastigiata accessions (COC149 and COC132). Group G3 mainly consisted of accessions belonging to subspecies fastigiata. The group consisted of 26 fastigiata accessions, three accessions of uncertain classification, one hypogaea accession (COC542) and a component line of the US variety Florunner. Group G1 had no preponderance of accessions of any subspecies and was classified as "mixed". The group had a total of 18 accessions consisting of 7 hypogaea and 9 fastigiata accessions and two individuals of uncertain subspecies. Group G4 had 12 minicore accessions including COC155. This group was heavily weighted towards subspecies fastigiata, with 3 Valencia accessions and 3 accessions (COC155, COC552, and COC157) that, based on field re-evaluation in 2010, were probably fastigiata var peruviana or aequatoriana, as well as COC763 which was a Virginia type that appeared to be similar in appearance above ground to a peruviana or aequatoriana type. A second feature distinguishing G4 from G1 was that in the latter, $83 \%$ of the accessions originated in South America; in G1, 83\% originated from Africa or Asia. Of the 11 minicore accessions that grouped along with $\mathrm{COC} 155$ in $\mathrm{G} 4$, ten had very low subgroup membership with a range of $31.5-48 \%$ if wild species and TxAG- 6 were included, and thus omission of wild species from the analysis had a significant effect on the composition of this subgroup. In the distance-based analysis, the two putative peruviana accessions in cluster $\mathrm{C} 2$ grouped close to COC155 (alone in Cluster D).

With wild species present, the model-based analysis also identified four groups in the population (Fig. 2b). Groups G1, G2 and G3 were similar to the earlier result and

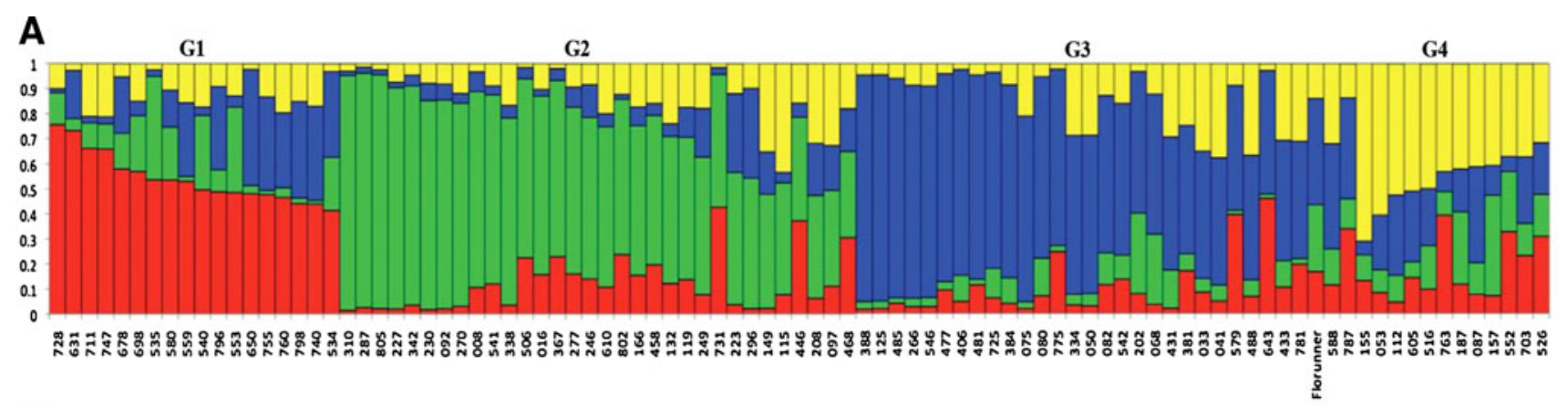

B

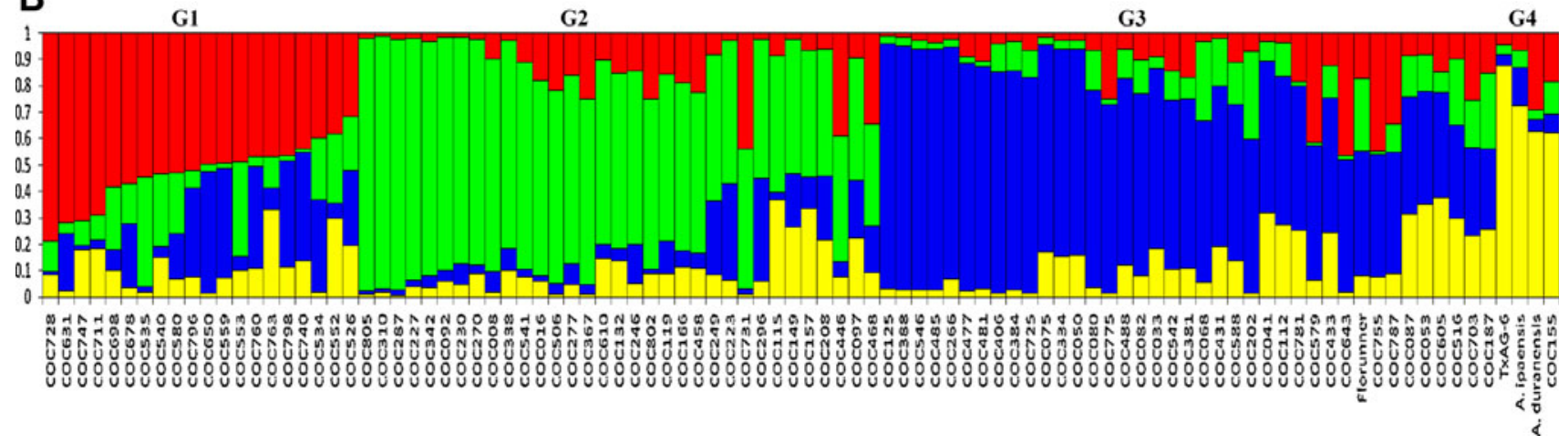

Fig. 2 Population structure assessed using the STRUCTURE program. a results with the 93 cultivated species accessions, b results with A. duranensis, A. ipaënsis, and TxAG-6 included. Numbers on the $y$-axis show the proportion of subgroup membership, and the legend on the $\mathrm{x}$-axis shows the accession names. Each accession is represented by a single vertical bar and is apportioned into 4 colored segments that represent that individual's estimated membership in each of the 4 clusters. G1 Mixed subgroup, G2 hypogaea subgroup, G3 fastigiata subgroup, G4 remaining group, including COC155 
corresponded to the mixed, hypogaea and fastigiata subgroups. However, group G4 was reduced by $67 \%$, with G4 consisting of the putative diploid progenitors A. duranensis and A. ipaënsis, COC155, and the amphidiploid TxAG-6.

Principal coordinate analysis (PCoA) clearly differentiated among subspecies (Fig. 3), the highest six eigenvalues (5.67, 3.66, 2.65, 2.45, 2.37 and 1.92), explaining 5.36, $4.32,3.80,3.45,3.19$ and $2.98 \%$ of variance, respectively. Using the first two principal coordinate axes, the fastigiata botanical type accessions mainly clustered in the first quadrant, and a few of them were also present in quadrant II. The hypogaea botanical type accessions clustered mainly in quadrant III. The individuals belonging to the mixed group were represented in quadrant IV. For the minicore accessions, the results corresponded well with both the distance- (UPGMA) and model-based (STRUCTURE) cluster analysis.

Population differentiation within and among subgroups in the US minicore collection

Analysis of molecular variance (AMOVA) within and among predefined subgroups (hypogaea subgroup, fastigiata subgroup, and mixed subgroup) demonstrated that differences among subgroups were highly significant $(P \leq 0.0001)$, with $16.87 \%$ of the total genetic variance being attributed to differences among subgroups, and $83.13 \%$ due to variation within subgroups (Table 3 ). The pairwise $F_{S T}$ provided estimates of genetic distances between the subgroups in the population and the subgroupspecific $F_{S T}$ explained the proportion of total genetic variance contained in a subgroup (the $S$ subscript) relative to the total genetic variance (the $T$ subscript) (see Table 4 ). Highest diversity was observed between the fastigiata and hypogaea subgroups $\left(F_{S T}=0.19\right)$ and the lowest was observed between the mixed and the fastigiata subgroups $\left(F_{S T}=0.12\right)$. Hence, it could be inferred that fastigiata and hypogaea subgroups have diverged to a greater extent as compared to the mixed and the fastigiata subgroups.

Similar results were obtained using Bayesian methods implemented using the program Hickory. The program was run multiple times and the smallest deviance information criterion (DIC) (3,097.52) (Spiegelhalter et al. 2002), Dbar (2,581.2) (measure of model fit) and pD (516.316) (effective number of parameters) (Holsinger and Wallace 2004) values were observed with the full model. The values of theta-II (analogous to Weir and Cockerham's $F_{S T}$ ), and Gst-B (Bayesian analog of Nei's $G_{S T}$ ), Nei (1973) were found to be 0.11 and 0.09 , respectively. This indicated the amount of differentiation among the predefined subgroups was $9-11 \%$, and the major proportion of the genetic variance was attributed to variation within subgroups.

Thus, the proportion of genetic variance among the predefined subgroups (both at the in group specific and pairwise level) being highly significant $(P \leq 0.0001)$ suggests the existence of population structure in the US minicore collection.

Linkage disequilibrium in the peanut genome

Linkage disequilibrium analysis revealed that $4.50 \%$ of SSR marker pairs were found to be in LD at $P \leq 0.01$.
Fig. 3 Principal coordinate analysis (PCoA) of 93 accessions obtained using NTSYS PC ver 2.0. Genotypes are encircled based on STRUCTURE results with wild species omitted, and the STRUCTURE groups are listed

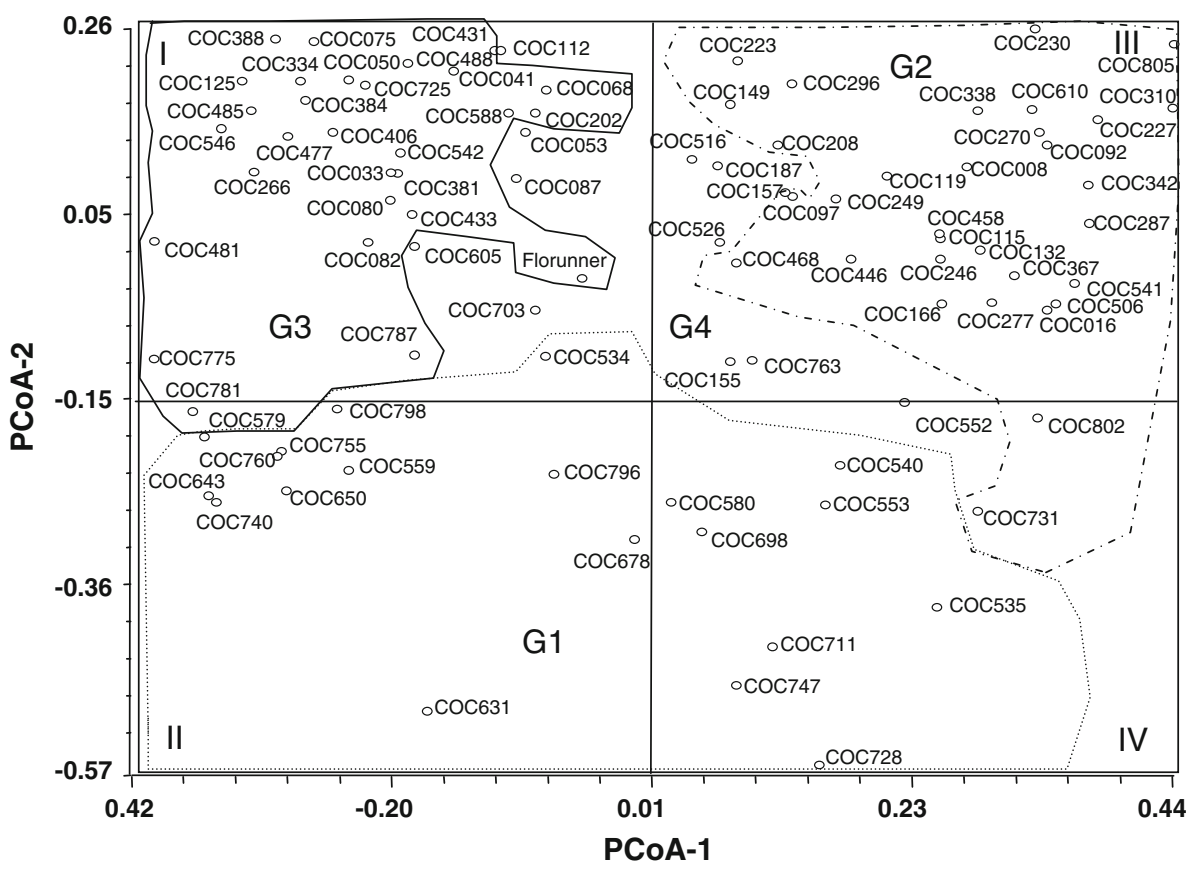


Table 3 Analysis of molecular variance (AMOVA)

\begin{tabular}{lrcccc}
\hline Source of variation & df* & Sum of squares & Variance components & Percentage of variation & $P$-value \\
\hline Among subgroups & 2 & 198.969 & 2.87793 & 16.87 & 83.13 \\
Within subgroups & 89 & $1,261.912$ & 14.17878 & & $<0.0001$ \\
Total & 91 & $1,460.880$ & 17.05671 & & \\
\hline
\end{tabular}

$* d f$ Degrees of freedom

Table 4 Pairwise genetic distances and subgroup specific $F_{S T}$ indices

\begin{tabular}{llll}
\hline Groups & Mixed subgroup & hypogaea subgroup & fastigiata subgroup \\
\hline Mixed subgroup & - & & \\
hypogaea subgroup & $0.1750^{*}$ & - & - \\
fastigiata subgroup & $0.1231^{*}$ & $0.1912^{*}$ & $0.1711^{*}$ \\
Diagonal elements & $0.1712^{*}$ & $0.1655^{*}$ \\
\hline
\end{tabular}

Diagonal elements are subgroup specific $F_{S T}$ 's; below diagonal elements are pairwise $F_{S T}$ 's

* Significant at $P<0.0001$

Table 5 Mean $\mathrm{r}^{2}$ and $\mathrm{D}^{\prime}$ values between locus pairs determined to be in $\mathrm{LD}(P \leq 0.01)$ for groups based on genetic distance

\begin{tabular}{lll}
\hline InterMarker distance $(\mathrm{cM})$ & ${\text { Average } \mathrm{r}^{2}}^{2}$ & ${\text { Average } \mathrm{D}^{\prime}}^{\prime}$ \\
\hline $0-10$ & 0.24 & 0.9 \\
$11-20$ & 0.12 & 0.85 \\
$21-50$ & 0.18 & 0.73 \\
$>50$ & 0.15 & 0.64 \\
Independent & 0.17 & 0.68 \\
\hline
\end{tabular}

Using a different criterion, $4.85 \%$ of SSR marker pairs had significant LD at the commonly-accepted criterion of $\mathrm{r}^{2} \geq 0.1 ; 1.37 \%$ of SSR marker pairs were in LD at $\mathrm{r}^{2} \geq 0.2$. This was based on 150 SSR markers that generated a total of 11,175 pairwise comparisons. To determine the effect of inter-marker distance on LD, SSR marker pairs were subdivided into five groups based on their intermarker genetic distance: tightly to moderately linked $(<10$ and 11-20 cM apart), loosely linked (21-50 and $>50 \mathrm{cM})$ (syntenic marker pairs), and marker pairs mapped on different linkage groups (non-syntenic marker pairs) (Table 5). Of the marker pairs with inter-marker genetic distances $<10 \mathrm{cM}, 11-20 \mathrm{cM}, 21-50 \mathrm{cM}$, and $>50 \mathrm{cM}$, and on different linkage groups, 19.33, 5.19, 6.25, 5.29 and $3.64 \%$ of marker pairs were in LD $(P \leq 0.01)$, respectively.

As this is the first report of measuring LD in peanut, an attempt was made to determine the threshold value of LD for different linkage-distance groupings of marker pairs. A 95\% confidence interval was determined based on the mean $\mathrm{r}^{2}(0.0225)$ value of unlinked marker pairs for all minicore accessions as done by Mather et al. (2007), plus a 1.969 pooled error variance of groups, making a threshold value of $\mathrm{r}^{2}=0.035$ for all marker pairs, and $\mathrm{r}^{2}=0.042$ for fastigiata marker pairs was estimated. For all minicore accessions, this corresponded to the 82nd percentile, as compared to the 75 th percentile value used by Mather et al. (2007). These values are lower than the typical value of 0.10 used by some authors. That the mean $r^{2}$ is low here may reflect that there are still a large number of marker pairs in linkage equilibrium, as well as a significant number in LD.

A straight line is drawn at 0.035 in the scatter plot of the LD measure $r^{2}$ (Fig. 4a) for the entire population. Linkage disequilibrium decay (Fig. 4c) indicated $10 \mathrm{cM}$ as an approximate measure of extent of LD useful for association studies in peanut over all minicore accessions. Linkage disequilibrium decay may be locus specific because differences in recombination rate, mutation rate, and selection history can affect LD patterns. The average values of $L D$ measures, $\mathrm{r}^{2}$ and $\mathrm{D}^{\prime}$ (Table 5) and the scatter plots (Fig. 4) clearly indicated high levels of LD among SSR marker pairs in the population. The high average values of LD measures $\mathrm{r}^{2}$ and $\mathrm{D}^{\prime}(0.17$ and 0.68$)$ observed for non-syntenic marker pairs in LD, suggested the presence of LD-generating factors other than linkage in the peanut genome.

A study of linkage disequilibrium was also attempted in the two major subgroups (fastigiata and hypogaea) identified by the model-based clustering method, in order to investigate further the influence of population structure on LD. However, there was not enough statistical power in the experiment in case of the hypogaea subgroup (33 genotypes and 108 markers after filtering for 5\% minor allele frequency). The fastigiata subgroup had 39 genotypes with 149 markers (after filtering for 5\% minor allele frequency) and thus provided reasonable power to perform the LD analysis. The threshold value of $r^{2}$ for unlinked marker pairs in the fastigiata subgroup was 0.042 and a straight 
Fig. 4 Scatter plots and decay plots with LD measure $\left(r^{2}\right)$ of marker pairs as a function of genetic distance $(\mathrm{cM})$. a Plot of LD statistic $r^{2}$ and genetic distance (cM) for entire population, b Plot of LD statistic $r^{2}$ and genetic distance (cM) for fastigiata group, $\mathbf{c}$ Plot of LD decay (population) with $r^{2}$ values for different linkage distance groups, $\mathbf{d}$ Plot of LD decay (fastigiata group) with $\mathrm{r}^{2}$ values for different linkage distance groups
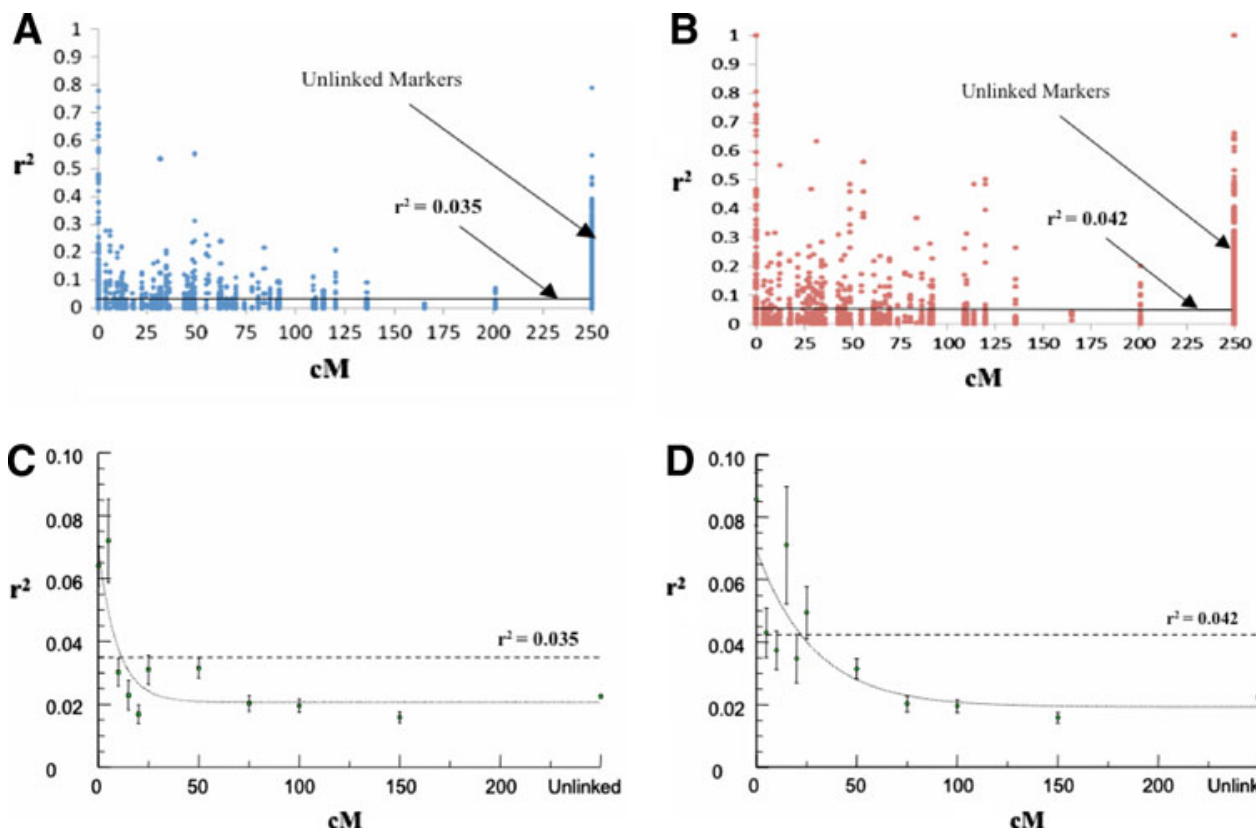

line is drawn in the scatter plot of the LD measure $r^{2}$ (Fig. 4b) for the fastigiata subgroup. The LD decay plot (Fig. 4d) shows high levels of LD in the fastigiata group and extended further as compared to the minicore, to approximately $20 \mathrm{cM}$. The proportion of marker pairs in LD $(P \leq 0.01)$ in the fastigiata subspecies with intermarker genetic distances of $0-10 \mathrm{cM}, 11-20 \mathrm{cM}$, 21-50 cM and $>50 \mathrm{cM}$, and on different linkage groups was $7.38,1.8,3.5,3.25$, and $0.82 \%$, respectively (Fig. 5). A comparison of LD in the entire germplasm set and the fastigiata subgroup is represented in the form of proportion of SSR marker pairs in LD (at $P \leq 0.01$ ) at genetic distances classified into five groups (see Fig. 5). Linkage disequilibrium among non-syntenic SSR marker pairs was drastically reduced (to $0.82 \%$ ) in the fastigiata subgroup. High average values of LD measures $r^{2}$ and $D^{\prime}(0.42$ and

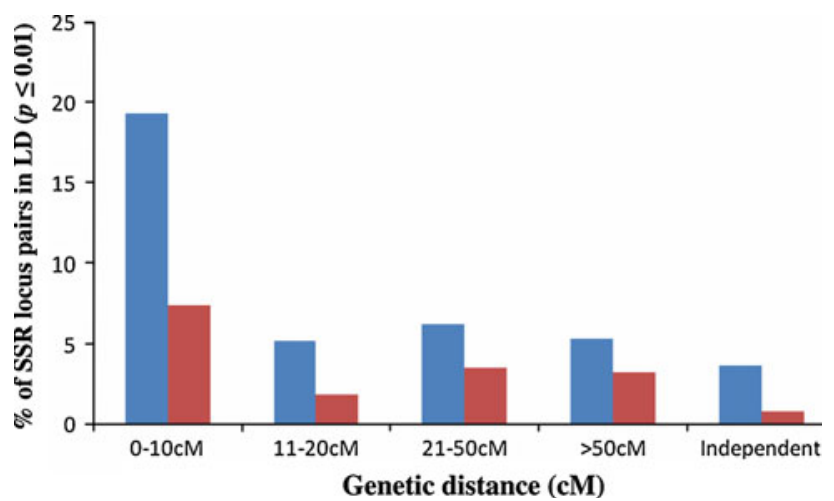

Fig. 5 Comparison of percentage of SSR locus pairs in LD (at $P \leq 0.01)$ in the entire population and the fastigiata subgroup. Solid (black) bars represent entire population and hollow (white) red bars represent the fastigiata subgroup
0.90) observed for non-syntenic marker pairs in LD suggests that some of these pairs may indeed be in LD.

\section{Discussion}

Morphological and molecular diversity, and population structure in the US minicore collection

The present study conducted with 392 SSR marker bands clearly depicted the structured diversity prevalent in the US minicore collection. The higher average number of bands per primer pair (12.3) witnessed in the study involving minicore and wild species was in accordance with the results of Barkley et al. (2007) (15.4 bands per primer pair). The most probable diploid progenitors, A. duranensis and A. ipaënsis, were found to have 53 and $43 \%$ unique bands respectively. This is in accord with RFLP data of Burow et al. (2009) suggesting presence of either other but unidentified diploid progenitors, or that a significant amount of genetic variation arose after hybridization of $A$. duranensis and A. ipaënsis.

Distance-based cluster analysis classified the US minicore collection on the basis of subspecies, hypogaea and fastigiata as observed in the earlier studies (Kottapalli et al. 2007; Barkley et al. 2007). The further division of fastigiata subcluster into two subgroups representing Valencia genotypes and a mix of Spanish and Valencia genotypes has also been reported in the study conducted by Naito et al. (2008) on the germplasm of Japan, as well as by Kottapalli et al. (2007).

Data from our study and another study (Barkley et al. 2007) suggest that botanical classification of peanut 
Table 6 Comparison of distance and model-based, and PCoA analysis

\begin{tabular}{|c|c|c|c|c|}
\hline & Group 1 (hypogaea) & Group 2 (fastigiata) & Mixed group & Group 4 \\
\hline Distance-based (UPGMA) & H-25; F-3; ND-14 & $\mathrm{H}-1 ; \mathrm{F}-29 ; \mathrm{ND}-2$ & $\begin{array}{l}\text { H-4; F-11; ND-2; } \\
\text { COC155; Florunner }\end{array}$ & $\begin{array}{l}\text { A. duranensis; A. ipaënsis; } \\
\text { TxAG-6 }\end{array}$ \\
\hline $\begin{array}{l}\text { Distance-based excluding wild } \\
\text { species and TxAG-6 }\end{array}$ & H-25; F-3; ND-14 & $\mathrm{H}-1 ; \mathrm{F}-29 ; \mathrm{ND}-2$ & $\begin{array}{l}\text { H-4; F-11; ND-2; } \\
\text { Florunner }\end{array}$ & COC155 \\
\hline Model-based (STRUCTURE) & H-20; F-3; ND-10 & $\begin{array}{l}\text { H-2; F-32; ND-4; } \\
\text { Florunner }\end{array}$ & $\mathrm{H}-8 ; \mathrm{F}-8 ; \mathrm{ND}-4$ & $\begin{array}{l}\text { A. duranensis; A. ipaënsis; } \\
\text { TxAG-6; COC155 }\end{array}$ \\
\hline $\begin{array}{l}\text { Model-based excluding wild } \\
\text { species and TxAG-6 }\end{array}$ & H-20; F-2; ND-10 & $\begin{array}{l}\text { H-1; F-26; ND-3; } \\
\text { Florunner }\end{array}$ & H-7; F-9; ND-2 & H-2; F-6; ND-3; COC155 \\
\hline PCoA & $\begin{array}{l}\text { H-20; F-4; ND-12 } \\
\text { (Quadrant 3) }\end{array}$ & $\begin{array}{l}\text { H-3; F-38; ND-4; } \\
\text { Florunner } \\
\text { (Quadrant } 1 \text { and 2) }\end{array}$ & $\begin{array}{l}\text { H-7; F-2; ND-2 } \\
\text { (Quadrant 4) }\end{array}$ & Not Applicable \\
\hline GRIN and field measurements & \multicolumn{4}{|c|}{ H-30; F-43; ND-18; COC155; Florunner; A. duranensis; A. ipaënsis; TxAG-6 } \\
\hline
\end{tabular}

Key H, Arachis hypogaea subspecies hypogea; F, Arachis fastigiata subspecies fastigiata; ND, not determined (uncertain)

accessions in GRIN was not accurate in some instances and needs further work. For example, COC132 (PI 497639) was classified in GRIN as subsp. fastigiata, but in our molecular analysis was placed in the hypogaea subcluster, and was reported by Barkley et al. (2007) to lack flowers on the mainstem, to have a spreading and bunch growth habit, rough pod reticulation, deep strangulation of pods, and a pod shape similar to botanical variety hirsuta. Thus, the authors suggested that the accession is probably A. hypogaea subspecies hypogaea var. hirsuta and not A. hypogaea subspecies fastigiata var. fastigiata. The present molecular study has also provided probable subspecies identity of the 14 minicore accessions with listed as having uncertain subspecies and market type due to discrepancies between field observation in Texas and those reported in GRIN; these clustered in the hypogaea subcluster in the current work, and many are likely to be hypogaea accessions.

Contrary to initial expectation, the subline of the US runner (subspecies hypogaea) cultivar Florunner was classified in the mixed subcluster of the UPGMA analysis, and in the fastigiata subgroup of the STRUCTURE analysis. However, knowing the parentage of Florunner, the results are credible-Florunner was derived from a cross made in 1960 of the varieties "Early Runner" and "Florispan" (Norden et al. 1969). "Florispan" is an A. hypogaea subspecies fastigiata var. vulgaris (Spanish) peanut, and so Florunner and its component lines are expected to have alleles derived from hypogaea and fastigiata subspecies, and therefore can be expected to be classified in the mixed subcluster in the present study.

Accession COC711 (PI 476025) present in the mixed subcluster is believed to be Arachis hypogaea subspecies fastigiata var. fastigiata based on field observations in GRIN. However, Barkley et al. (2007) reported that the accession has flowers on the main axis, dark green leaves, rough pod reticulation, deep strangulation of pods and was collected in Peru, and considered that this accession should be classified in subspecies fastigiata due to the flowers on the main axis but may be variety peruviana or aequatoriana rather than variety fastigiata. Observation in Texas in 2010 confirms this observation. Another example is accession COC542 (PI 370331), which is listed as a hypogaea subspecies and Virginia market type based on our observations in 2006 and 2010, as well as in GRIN, but was classified in the fastigiata subcluster based on SSR data. However, this accession is reported as having the "mixed" market type by Barkley et al. (2007). Collaborative evaluation of the subspecies and botanical varieties is underway, and it is hoped that this will clear up such ambiguities.

\section{Comparison of distance and model-based diversity} analyses, and significance of the "mixed" cluster

Results of the model-based method were largely in accord with the results obtained using the distance-based method, with a few exceptions. A comparison of the results obtained using both distance and model-based methods, and PCoA are highlighted in Table 6. Interestingly, all the 10 accessions of uncertain subspecies found in the group G2 (hypogaea subgroup) were found in the subcluster hypogaea (A) in the distance-based method. This suggests that these accessions may be hypogaea botanical varieties. As per GRIN, of the 10 accessions, 4 accessions were classified as hypogaea botanical varieties, 1 accession was fastigiata botanical variety, and the subspecies of the remaining 5 accessions were uncertain.

Eleven of 20 accessions in the group G1 (mixed subgroup) were found clustered in the mixed subcluster $\mathrm{C}$ identified in the distance-based method, suggesting either that these accessions may have been the products of previous hybridization between subspecies, that additional morphological study is needed to correct errors in classification, or that chance combinations of alleles result in some accessions having proportions of alleles not 
concordant with morphological observations. Evidence suggests that all three explanations may be contributing to the "mixed" cluster. In favor of a genetic justification for the "mixed" group are the additional grouping results and the principal coordinate analyses. The pairwise $F_{S T}$ values indicated that the mixed subgroup was separated from the fastigiata subgroup at a significant genetic distance. The history of Florunner gives evidence for mixed ancestry, and it was observed previously (Krishna et al. 2004) that certain Valencia accessions grouped separately from others based on SSR analysis, and that these accessions were hybrids between runner and Valencia peanuts.

The composition of group G4 varied considerably between analyses with and without the presence of the wild species and synthetic amphidiploid. There was a high proportion of peruviana and aequatoriana accessions in this group. In either case, G4 contained COC155 (PI 502111), which was collected from Peru. This accession appears to be Arachis hypogaea subspecies fastigiata variety peruviana, based on 2010 field evaluations (Burow, unpublished). Results suggest significant distance from other minicore accessions, and unexpected similarity to the wild species accessions. Also, in the distance-based cluster analysis, this accession was distinct from all the other minicore accessions. It is not clear why both distance-based and model-based methods place this accession so close to the wild species.

Supporting the need for further morphological study are differences in classification of some accessions among GRIN, Barkley et al. (2007), and our observations. One important consideration supporting the idea that there may be some errors in classification is that, of the six botanical varieties of peanut, hypogaea, hirsuta, fastigiata, vulgaris, aequatoriana and peruviana, only three, hypogaea, fastigiata and vulgaris are common to the US, and so the other three botanical varieties could be misidentified more easily. We suggest that a careful morphological re-evaluation may be useful for the accessions of uncertain subspecies and botanical variety, as well as perhaps for the accessions represented in the mixed subgroup. The peanut crop germplasm committee has requested a re-evaluation of the minicore collection (Burow MD, personal communication), and our 2010 field evaluation of these materials is part of this effort.

Finally, COC542 and COC155 may be examples where chance combinations of alleles may not represent morphological data. In the case of COC542, all morphological descriptions agree that this is subspecies hypogaea, but the molecular data place this accession as more similar to fastigiata than hypogaea. In the case of COC155, the accession is clearly not a wild species (C. Simpson, personal communication), but groups with the wild species based on Bayesian analysis of SSR data. Omitting wild species, COC155 groups as expected in group G4 with other similar accessions.

Results of the AMOVA test indicated that the subgroup specific $F_{S T}$ values were almost the same for all the subgroups, highlighting that none of the subgroups individually has undergone selective evolution. This is in accordance with the history of origin of peanut (Simpson et al. 2002). The analysis indicated the presence of a reasonable amount of variation in the US minicore collection that could be exploited to broaden the genetic base of peanut cultivars.

\section{Linkage disequilibrium in the peanut genome}

A first attempt was made to investigate the nature of LD in the peanut genome. Some pairs of syntenic SSR markers were found to be in strong LD. Linkage disequilibrium due to linkage useful for association studies was approximately estimated to be around $10 \mathrm{cM}$, and was also found to extend to perhaps $20 \mathrm{cM}$ in subspecies fastigiata. However, the low threshold (0.035) and $r^{2}$ means of linked groups suggests some caution in interpretation. Although there is significant LD among linked markers to $10 \mathrm{cM}$ overall or $20 \mathrm{cM}$ in subspecies fastigiata, there are many marker pairs that are not in LD. The small number of markers, uneven distribution of linkage distances, use of a composite linkage map to estimate distance, and known variation in $\mathrm{LD}$ among regions in the genome suggest the possibility for large differences from region-to-region or even marker-to-marker. Existence of long ranges of LD between marker pairs is expected for a highly-selfing crop. Several other studies have reported LD extending to large distances in self-pollinating crops. For instance, linkage disequilibrium extends between $50-100 \mathrm{cM}$ in local Michigan populations of Arabidopsis (Abdurakhmonov and Abdukarimov 2008), to $30 \mathrm{cM}$ in RIL populations of wheat (Tommasini et al. 2007), $50-200 \mathrm{cM}$ in rice (Agrama and Eizenga 2008) and 10 to $50 \mathrm{cM}$ in barley, depending on the germplasm assayed (Kraakman et al. 2004; Malysheva-Otto et al. 2006).

In addition to being a highly self-pollinating crop, cultivated peanut (A. hypogaea $\mathrm{L}$.) has undergone a genetic bottleneck as a result of a single domestication event about 3,500 years ago (Simpson et al. 2002). This would have resulted in fewer allelic combinations being passed on to the subsequent generations and would have induced high amounts of LD. Similarly, in the case of human LD studies, the Finnish population has been largely exploited to identify causal variants associated with disease traits, as it is believed to have undergone a genetic bottleneck (Hastbacka et al. 1992).

The percentage of SSR marker pairs found to be in LD at different significance levels ( $P$-values) was intermediate 
compared to published reports for other crops. Recent literature reports greater than $50 \%$ of SSR loci pairs being in LD (Kraakman et al. 2004; Maccaferri et al. 2005; Stich et al. 2005; Stich et al. 2006). Linkage disequilibrium comparable to that in peanut was reported using SSR marker pairs in several species-8.7\% in sorghum (Hamblin et al. 2004), 13\% in allopolyploid cotton (Abdurakhmonov et al. 2009), and 9.7\% in maize (Remington et al. 2001). There are also reports of lower percentage of LD, such as $1.5 \%$ of pairs in case of maize (Tenaillon et al. 2001).

Although lower percentages of SSR marker pairs in LD were determined at more-stringent significance levels, LD was seen to persist between marker pairs even at highlystringent $r^{2}$ measures $\left(r^{2} \geq 0.2\right)$. This suggests the possibility of finding markers explaining high amount of phenotypic variance and the existence of probable haplotype blocks in the peanut genome that could be exploited using association mapping.

In addition, some non-syntenic SSR marker pairs were in LD even using high statistical thresholds $(P \leq 0.01)$. Peanut breeding programs have relied almost exclusively on crossing elite breeding lines for developing improved cultivars (Knauft and Gorbet 1989) because the cultivated peanut is isolated reproductively from its wild relatives (Hopkins et al. 1999). As a result, high selection pressure would have been applied on favorable alleles over the generations resulting in LD between non-syntenic loci pairs. Epistatic selection is also reported in peanut, between genes controlling some vital traits in segregating populations (Isleib et al. 1978; Layrisse et al. 1980; Isleib and Wynne 1983). Hence, selection might be one of the factors inducing LD between unlinked loci pairs in the peanut genome.

Comparison of the proportions of marker pairs in LD in the entire population and the fastigiata subgroup revealed considerable influence of population structure on LD. Some syntenic marker pairs with inter-marker genetic distances less than $50 \mathrm{cM}$ as well as greater than $50 \mathrm{cM}$ revealed a significant proportion of marker pairs in $\mathrm{LD}$, in both the entire population and the fastigiata subgroup, confirming LD extending to longer distances in case of peanut. However, the drastic reduction to $0.82 \%$ in the proportion of non-syntenic markers pairs in LD in case of the fastigiata subgroup, suggests strong influence of population structure on LD, as observed in case of Maccaferri et al. (2005). The effect of population structure on LD suggests that population structure and relatedness should be taken into serious account in future association mapping studies involving the US peanut minicore collection in order to reduce false positives and perform unbiased association mapping. Finally, as LD stretches to longer distances in peanut relative to maize (Tenaillon et al. 2001; Remington et al. 2001; Thornsberry et al. 2001), for example, comparatively fewer markers would be required to perform genome-wide association studies in peanut. From the LD decay plot (Fig. 4c) it would be reasonable to assume markers separated by a genetic distance of $\leq 10 \mathrm{cM}$ to have the greatest chance to be in $\mathrm{LD}$ due to linkage. As LD is higher at $5 \mathrm{cM}$, assuming markers spaced every $5 \mathrm{cM}$ and a peanut genome of size 2,210 $\mathrm{cM}$ (Burow et al. 2009), about 450 evenly- spaced markers would be a good initial estimate of the number of markers needed for effective association mapping.

By contrast, for QTL mapping, peanut has relatively low polymorphism among SSR markers in cultivated germplasm. In the past year, there have been three SSR marker based linkage maps developed using cultivated tetraploid genotypes (Hong et al. 2008; Varshney et al. 2009a; Hong et al. 2009). However, all three maps are not dense and have limited polymorphism between the parents of the mapping population. Hong et al. (2008), Varshney et al. (2009a) and Hong et al. (2009) reported 13.5, 12.6 and $11.59 \%$ polymorphic markers, respectively. Screening of 1,000 markers would provide just over 100 polymorphic markers useful for constructing a map. Also, allotetraploid peanut, having a large genome of around $3 \times 10^{9} \mathrm{bp}$ (Varshney et al. 2009b), comparable to that of the human genome, would require a large number of polymorphic markers to make maps sufficiently dense to permit mapbased cloning of genes controlling important traits. Consequently, application of LD mapping would be less time consuming, less expensive, would need minimal resources and will greatly accelerate the identification of potential loci associated with biotic and abiotic stresses.

However, LD extending to greater distances in the peanut genome would limit the resolution of LD based mapping and eventually markers found associated with a trait of interest by LD based mapping would have to be validated using linkage mapping. Thus, considering the nature of the peanut genome and the preliminary results obtained in the LD analysis performed using markers on some of the linkage groups, it could be postulated that LD based mapping together with bi-parental mapping will be effective for identifying and validating markers associated with traits of interest. Although the present study has provided a first insight of LD in the peanut genome using US minicore collection, it should be noted that, this conclusion is preliminary and needs further exploration, due to the polyploid nature of peanut genome, the dominantlycoded SSR data, the non-uniform distribution of markers over the linkage groups, use of a composite linkage map, and the coverage being limited to approximately $25 \%$ of the peanut genome. 
Acknowledgments The authors would like to thank Drs. Corley Holbrook and Roy Pittman for providing the US minicore accessions used in this study, Dr. N. Sathyanarayana and M. Leelambika for their guidance in diversity analysis, and to Drs. Z. Xin, C. E. Simpson and J. F. M. Valls for helpful discussions. This work was supported with the funding from Ogallala Aquifer Initiative, the Peanut Collaborative Research Support Project, the Texas Peanut Producers Board, the National Peanut Board, and the Texas Tech University Office of the Vice President for Research.

\section{References}

Abdurakhmonov IY, Abdukarimov A (2008) Application of association mapping to understanding the genetic diversity of plant germplasm resources. Int J Plant Genomics 2008:574927

Abdurakhmonov IY, Saha S, Jenkins JN, Buriev ZT, Shermatov SE, Scheffler BE, Pepper AE, Yu JZ, Kohel RJ, Abdukarimov A (2009) Linkage disequilibrium based association mapping of fiber quality traits in G. hirsutum L. variety germplasm. Genetica 136:401-417

Agrama H, Eizenga G (2008) Molecular diversity and genome-wide linkage disequilibrium patterns in a worldwide collection of Oryza sativa and its wild relatives. Euphytica 160:339-355

Barkley NA, Dean RE, Pittman RN, Wang ML, Holbrook CC, Pederson GA (2007) Genetic diversity of cultivated and wildtype peanuts evaluated with M13-tailed SSR markers and sequencing. Genet Res 89:93-106

Barrett BA, Kidwell KK (1998) AFLP-based genetic diversity assessment among wheat cultivars from the Pacific Northwest. Crop Sci 38:1261-1271

Breseghello F, Sorrells ME (2006) Association mapping of kernel size and milling quality in wheat (Triticum aestivum L.) cultivars. Genetics 172:1165-1177

Buckler ES, Thornsberry JM (2002) Plant molecular diversity and applications to genomics. Curr Opin Plant Bio 5:107-111

Burow MD, Simpson CE, Starr JL, Paterson AH (2001) Transmission genetics of chromatin from a synthetic amphidiploid to cultivated peanut (Arachis hypogaea L.): Broadening the gene pool of a monophyletic polyploid species. Genetics 159:823-837

Burow MD, Simpson CE, Faries MW, Starr JL, Paterson AH (2009) Molecular biogeographic study of recently described B- and A-genome Arachis species, also providing new insights into the origins of cultivated peanut. Genome 52:107-119

Cuc L, Mace E, Crouch J, Quang V, Long T, Varshney R (2008) Isolation and characterization of novel microsatellite markers and their application for diversity assessment in cultivated groundnut (Arachis hypogaea). BMC Plant Biol 8:55

Evanno G, Regnaut S, Goudet J (2005) Detecting the number of clusters of individuals using the software STRUCTURE: a simulation study. Mol Ecol Notes 14:2611-2620

Excoffier L, Smouse PE, Quattro JM (1992) Analysis of molecular variance inferred from metric distances among DNA haplotypes: application to human mitochondrial DNA restriction data. Genetics 131:479-491

Excoffier L, Laval G, Schneider S (2005) Arlequin (version 3.0): an integrated software package for population genetics data analysis. Evol Bioinform Online 1:47-50

Falush D, Stephens M, Pritchard JK (2003) Inference of population structure using multilocus genotype data: linked loci and correlated allele frequencies. Genetics 164:1567-1587

Falush D, Stephens M, Pritchard JK (2007) Inference of population structure using multilocus genotype data: dominant markers and null alleles. Mol Ecol Notes 7:574-578
Fávero AP, Simpson CE, Valls JFM, Vello NA (2006) Study of the evolution of cultivated peanut through crossability studies among Arachis ipaënsis, A. duranensis, and A. hypogaea. Crop Sci 46:1546-1622

Ferguson M, Burow M, Schulze S, Bramel P, Paterson A, Kresovich S, Mitchell S (2004a) Microsatellite identification and characterization in peanut (A. hypogaea L.). Theor Appl Genet 108:1064-1070

Ferguson ME, Bramel PJ, Chandra S (2004b) Gene diversity among botanical varieties in peanut (Arachis hypogaea L.). Crop Sci 44:1847-1854

Flint-Garcia SA, Thornsberry JM, Buckler ES (2003) Structure of linkage disequilibrium in plants. Annu Rev Plant Biol 54:357-374

Foncéka D, Hodo-Abalo T, Rivallan R, Faye I, Sall M, Ndoye O, Fávero A, Bertioli D, Glaszmann J-C, Courtois B, Rami J-F (2009) Genetic mapping of wild introgressions into cultivated peanut: a way toward enlarging the genetic basis of a recent allotetraploid. BMC Plant Biol 9:103

Gomez SM, Simpson CE, Vikas PB, Puppala N, Payton P, Burke JJ, Paterson AH, Guo BZ, Reddy OUK, Burow MD (2008) Towards an integrated SSR/RFLP map of tetraploid peanut. Third International Conference of the Peanut Research Community, ICRISAT, Hyderabad, Andhra Pradesh, India. p 21 (4-8 Nov 2008)

Gower JC (1966) Some distance properties of latent root and vector methods used in multivariate analysis. Biometrika 53:325-338

GR IBP (1992) Descriptors for groundnut. Int Board of Plant Genet Res Rome and Int Crops Res Inst For the Semi-Arid Tropics, Patancheru, India

Hamblin MT, Mitchell SE, White GM, Gallego J, Kukatla R, Wing RA, Paterson AH, Kresovich S (2004) Comparative population genetics of the panicoid grasses: sequence polymorphism, linkage disequilibrium and selection in a diverse sample of sorghum bicolor. Genetics 167:471-483

Hastbacka J, de la Chapelle A, Kaitila I, Sistonen P, Weaver A, Lander E (1992) Linkage disequilibrium mapping in isolated founder populations: diastrophic dysplasia in Finland. Nat Genet 2:204-211

He G, Meng R, Newman M, Gao G, Pittman R, Prakash C (2003) Microsatellites as DNA markers in cultivated peanut (Arachis hypogaea L.). BMC Plant Biol 3:3

He G, Meng R, Gao H, Guo B, Gao G, Newman M, Pittman RN, Prakash CS (2005) Simple sequence repeat markers for botanical varieties of cultivated peanut (Arachis hypogaea L.). Euphytica 142:131-136

Holbrook CC, Dong W (2005) Development and evaluation of a mini core collection for the US peanut germplasm collection. Crop Sci 45:1540-1544

Holbrook CC, Anderson WF, Pittman RN (1993) Selection of a core collection from the US Germplasm collection of Peanut. Crop Sci 33:859-861

Holsinger KE, Lewis PO (2003) HICKORY: a package for analysis of population genetic data, version 1.0. Department of Ecology and Evolutionary Biology, University of Connecticut. Storrs, Connecticut, USA

Holsinger KE, Wallace LE (2004) Bayesian approaches for the analysis of population genetic structure: an example from Platanthera leucophaea (Orchidaceae). Mol Ecol 13:887-894

Holsinger KE, Lewis PO, Dey DK (2002) A Bayesian approach to inferring population structure from dominant markers. Molecular Ecol 11:1157-1164

Hong Y, Liang X, Chen X, Liu H, Zhou G, Li S, Wen S (2008) Construction of genetic linkage map based on SSR markers in peanut (Arachis hypogaea L.). Agric Sci China 7:915-921 
Hong Y, Liang X, Chen X, Liu H, Zhou G, Li S, Wen S (2009) Construction of genetic linkage map in Peanut (Arachis hypogaea L.) Cultivars. Acta Agronomica Sinica 35:395-402

Hopkins MS, Casa AM, Wang T, Mitchell SE, Dean RE, Kochert GD, Kresovich S (1999) Discovery and characterization of polymorphic simple sequence repeats (SSRs) in peanut. Crop Sci 39:1243-1247

Huang Q, Borner A, Röder S, Ganal W (2002) Assessing genetic diversity of wheat (Triticum aestivum L.) germplasm using microsatellite markers. Theor Appl Genet 105:699-707

Husted L (1936) Cytological studies on the peanut, Arachis. II. Chromosome number, morphology and behavior, and their application to the problem of the origin of the cultivated forms. Cytologia 7:396-422

Isleib TG, Wynne JC (1983) Heterosis in testcrosses of 27 exotic peanut cultivars. Crop Sci 23:832-841

Isleib TG, Wynne JC, Rawlings JO (1978) Estimates of epistasis for diverse peanut cultivars. Peanut Sci 5:106-108

Jannink J, Bink MC, Jansen RC (2001) Using complex plant pedigrees to map valuable genes. Trends Plant Sci 6:337-342

Jansen RC, Jannink J-L, Beavis WD (2003) Mapping quantitative trait loci in plant breeding populations: use of parental haplotype sharing. Crop Sci 43:829-834

Knauft DA, Gorbet DW (1989) Genetic diversity among peanut cultivars. Crop Sci 29:1417-1422

Knowler WC, Williams RC, Pettitt DJ, Steinberg AG (1988) Gm3;5, 13, 14 and type 2 diabetes mellitus: an association in American Indians with genetic admixture. Am J Hum Genet 43:520-526

Kochert G, Stalker HT, Gimenes M, Galgaro L, Lopes CR, Moore K (1996) RFLP and cytological evidence on the origin and evolution of allotetraploid domesticated peanut, Arachis hypogaea (Leguminosae). Am J Bo. 83:1282-1291

Kottapalli KR, Burow MD, Burow G, Burke J, Puppala N (2007) Molecular characterization of the US peanut mini core collection using microsatellite markers. Crop Sci 47:1718-1727

Kraakman ATW, Niks RE, Van den Berg PMMM, Stam P, Van Eeuwijk FA (2004) Linkage disequilibrium mapping of yield and yield stability in modern spring barley cultivars. Genetics 168:435-446

Krapovickas A, Gregory WC (1994) Taxonomía del género Arachis (Leguminosae). Bonplandia 8:1-186

Krishna GK, Zhang J, Burow M, Pittman RN, Delikostadinov SG, Lu Y, Puppala N (2004) Genetic diversity analysis in Valencia peanut (Arachis hypogaea L.) using microsatellites. Cell Mol Bio Lett 9:685-697

Layrisse AJ, Wynne JC, Isleib TG (1980) Combining ability for yield, protein, and oil of peanut lines from South American centers of diversity. Euphytica 29:561-570

Li Y, Li Y, Wu S, Han K, Wang Z, Hou W, Zeng Y, Wu R (2007) Estimation of multilocus linkage disequilibria in diploid populations with dominant markers. Genetics 176:1811-1821

Liu K, Muse SV (2005) PowerMarker: an integrated analysis environment for genetic marker analysis. Bioinformatics 21:2128-2129

Maccaferri M, Sanguineti MC, Noli E, Tuberosa R (2005) Population structure and long-range linkage disequilibrium in a durum wheat elite collection. Mol Breeding 15:271-290

Mace E, Phong D, Upadhyaya H, Chandra S, Crouch J (2006) SSR analysis of cultivated groundnut (Arachis hypogaea L.) germplasm resistant to rust and late leaf spot diseases. Euphytica $152: 317-330$

Malysheva-Otto L, Ganal M, Roder M (2006) Analysis of molecular diversity, population structure and linkage disequilibrium in a worldwide survey of cultivated barley germplasm (Hordeum vulgare L.). BMC Genet 7:6

Mantel N (1967) The detection of disease clustering and a generalized regression approach. Cancer Res 27:209-220
Mather KA, Caicedo AL, Polato NR, Olsen KM (2007) The extent of linkage disequilibrium in rice (Oryza sativa L.). Genetics 177:2223-2232

McRae AF, McEwan JC, Dodds KG, Wilson T, Crawford AM, Slate J (2002) Linkage disequilibrium in domestic sheep. Genetics 160:1113-1122

Melchinger AE, Graner A, Singh M, Messmer M (1994) Relationships among European barley germplasm: I. Genetic diversity among winter and spring cultivars revealed by RFLPs. Crop Sci 34:1191-1199

Mohlke KL, Lange EM, Valle TT, Ghosh S, Magnuson VL, Silander $\mathrm{K}$, Watanabe RM, Chines PS, Bergman RN, Tuomilehto J, Collins FS, Boehnke M (2001) Linkage disequilibrium between microsatellite markers extends beyond $1 \mathrm{cM}$ on chromosome 20 in Finns. Genome Res 11:1221-1226

Moretzsohn M, Leoi L, Proite K, Guimarães P, Leal-Bertioli S, Gimenes M, Martins W, Valls J, Grattapaglia D, Bertioli D (2005) A microsatellite-based, gene-rich linkage map for the AA genome of Arachis (Fabaceae). Theor Appl Genet 111:1060-1071

Naito Y, Suzuki S, Iwata Y, Kuboyama T (2008) Genetic diversity and relationship analysis of peanut germplasm using SSR markers. Breeding Science 58:293-300

Nei M (1973) Analysis of gene diversity in subdivided populations. Proc Natl Acad Sci USA 70:3321-3323

Norden AJ, Lipscomb RW, Carver WA (1969) Registration of Florunner Peanuts (Reg. No. 2). Crop Sci 9:850

Nwokolo E, Smartt J (1996) Food and feed from legumes and oilseeds. Chapman and Hall, London

Palmieri DA, Hoshino AA, Bravo JP, Lopes CR, Gimenes MA (2002) Isolation and characterization of microsatellite loci from the forage species Arachis pintoi (Genus Arachis). Mol Ecol Notes 2:551-553

Palmieri DA, Bechara MD, Curi RA, Gimenes MA, Lopes CR (2005) Novel polymorphic microsatellite markers in section Caulorrhizae Arachis, Fabaceae. Mol Ecol Notes 5:77-79

Pimratch S, Jogoly S, Toomsan B, Jaisil P, Kesmala T, Patanothai A (2004) Heritability and correlation for nitrogen fixation and agronomic traits of peanut (Arachis hypogaea L). Songklanakarin J Sci Technol 26:305-315

Pritchard JK, Wen W (2004) Documentation for Structure software. The University of Chicago Press, Chicago

Pritchard JK, Stephens M, Donnelly P (2000) Inference of population structure using multilocus genotype data. Genetics 155:945-959

Pritchard JK, Wen X, Falush D (2007) Documentation for structure software: Version 2.2. Department of Human Genetics, University of Chicago; Department of Statistics, University of Oxford. Available at http://pritch.bsd.uchicago.edu/software

Rafalski A, Morgante M (2004) Corn and humans: recombination and linkage disequilibrium in two genomes of similar size. Trends Genet 20:103-111

Remington DL, Thornsberry JM, Matsuoka Y, Wilson LM, Whitt SR, Doebley J, Kresovich S, Goodman MM, Buckler ES (2001) Structure of linkage disequilibrium and phenotypic associations in the maize genome. Proc Natl Acad Sci USA 98:11479-11484

Reynolds J, Weir BS, Cockerham CC (1983) Estimation of the coancestry coefficient: basis for a short-term genetic distance. Genetics 105:767-779

Rohlf FJ (2000) NTSYS-pc Numerical taxonomy and multivariate analysis system. Appl. Biostatics, Inc., New York, USA

Sand P (2007) A lesson not learned: allele misassignment. Behav Brain Funct 3:65

Sawkins M, Farmer A, Hoisington D, Sullivan J, Tolopko A, Jiang Z, Ribaut JM (2004) Comparative Map and Trait Viewer (CMTV): an integrated bioinformatic tool to construct consensus maps and compare QTL and functional genomics data across genomes and experiments. Plant Mol Biol 56:465-480 
Seijo JG, Lavia GI, Fernandez A, Krapovickas A, Ducasse D, Moscone EA (2004) Physical mapping of the 5S and 18S-25S rRNA genes by FISH as evidence that Arachis duranensis and A. ipaënsis are the wild diploid progenitors of A. hypogaea (Leguminosae). Am J Bot 91:1294-1303

Seijo G, Lavia GI, Fernandez A, Krapovickas A, Ducasse DA, Bertioli DJ, Moscone EA (2007) Genomic relationships between the cultivated peanut (Arachis hypogaea, Leguminosae) and its close relatives revealed by double GISH. Am J Bot 94: 1963-1971

Simpson CE, Nelson SC, Starr JL, Woodard KE, Smith OD (1993) Registration of TxAG-6 and TxAG-7 peanut germplasm lines. Crop Sci 33:1418

Simpson CE, Krapovickas A, Valls JM (2002) History of Arachis including evidence of A. hypogaea progenitors. Peanut Sci 28:79-81

Sneath PHA, Sokal RR (1973) Numerical taxonomy. Freeman, San Francisco

Sokal RR, Michener CD (1958) A statistical method for evaluating systematic relationships. University of Kansas Scientific Bulletin 28:1409-1438

Sokal RR, Sneath PHA (1963) Principles of Numerical Taxonomy. W, H. Freeman, San Francisco

Spiegelhalter DJ, Best NG, Carlin BP, Avd Linde (2002) Bayesian measures of model complexity and fit. J R Statist Soc B 64:583-639

Stebbins CD (1957) Genetics, evolution, and plant breeding. Indian J Genet Plant Breed 17:129-141

Stich B, Melchinger AE, Frisch M, Maurer HP, Heckenberger M, Reif JC (2005) Linkage disequilibrium in European elite maize germplasm investigated with SSRs. Theor Appl Genet 111: 723-730

Stich B, Maurer H, Melchinger A, Frisch M, Heckenberger M, van der Voort J, Peleman J, Sørensen A, Reif J (2006) Comparison of linkage disequilibrium in elite European maize inbred lines using AFLP and SSR markers. Mol Breeding 17:217-226
Tang R, Gao G, He L, Han Z, Shan S, Zhong R, Zhou C, Jiang J, Li Y, Zhuang W (2007) Genetic diversity in cultivated groundnut based on SSR markers. J Genet Genomics 34:449-459

Tenaillon MI, Sawkins MC, Long AD, Gaut RL, Doebley JF, Gaut BS (2001) Patterns of DNA sequence polymorphism along chromosome 1 of maize (Zea mays ssp. mays L.). Proc Natl Acad Sci USA 98:9161-9166

Thornsberry JM, Goodman MM, Doebley J, Kresovich S, Nielsen D, Buckler ES (2001) Dwarf8 polymorphisms associate with variation in flowering time. Nat Genet 28:286-289

Tommasini L, Schnurbusch T, Fossati D, Mascher F, Keller B (2007) Association mapping of Stagonospora nodorum blotch resistance in modern European winter wheat varieties. Theor Appl Genet 115:697-708

Varshney R, Bertioli D, Moretzsohn M, Vadez V, Krishnamurthy L, Aruna R, Nigam S, Moss B, Seetha K, Ravi K, He G, Knapp S, Hoisington D (2009a) The first SSR-based genetic linkage map for cultivated groundnut (Arachis hypogaea L.). Theor Appl Genet 118:729-739

Varshney RK, Mahendar T, Aruna R, Nigam SN, Neelima K, Vadez V, Hoisington DA (2009b) High level of natural variation in a groundnut (Arachis hypogaea L.) germplasm collection assayed by selected informative SSR markers. Plant Breeding 128:486-494

Wang M, Zhu C, Barkley N, Chen Z, Erpelding J, Murray S, Tuinstra M, Tesso T, Pederson G, Yu J (2009) Genetic diversity and population structure analysis of accessions in the US historic sweet sorghum collection. Theor Appl Genet 120:13-23

Weir B (1996) Genetic data analysis 2: methods for discrete population genetic data. Sinauer Associates

Weir BS, Cockerham CC (1984) Estimating f-statistics for the analysis of population structure. Evol Int $\mathrm{J}$ Org Evol 38:1358-1370

Weir BS, Hill WG (2002) Estimating F-statistics. Ann Rev Genet 36:721-750

Whitt SR, Buckler ES (2003) Using natural allelic diversity to evaluate gene function. Humana Press pp 123-139 